Article

\title{
Free Vibration Analysis of Laminated Functionally Graded Carbon Nanotube-Reinforced Composite Doubly Curved Shallow Shell Panels Using a New Four-Variable Refined Theory
}

\author{
Vu Van Tham, Tran Huu Quoc* and Tran Minh Tu@ \\ Faculty of Industrial and Civil Engineering, National University of Civil Engineering, Hanoi 100000, Vietnam; \\ thamvv@nuce.edu.vn (V.V.T.); tutm@nuce.edu.vn (T.M.T.) \\ * Correspondence: thquoc@gmail.com; Tel.: +84-916-600-081
}

Received: 31 October 2019; Accepted: 28 November 2019; Published: 1 December 2019

check for updates

\begin{abstract}
In this paper, a new four-variable refined shell theory is developed for free vibration analysis of multi-layered functionally graded carbon nanotube-reinforced composite (FG-CNTRC) doubly curved shallow shell panels. The theory has only four unknowns and satisfies zero stress conditions at the free surfaces without correction factor. Five different types of carbon nanotube (CNTs) distribution through the thickness of each FG-CNT layer are considered. Governing equations of simply supported doubly curved FG-CNTRC panels are derived from Hamilton's principle. The resultant eigenvalue system is solved to obtain the frequencies and mode shapes of the anti-symmetric cross-ply laminated panels by using the Navier solution. The numerical results in the comparison examples have proved the accuracy and efficiency of the developed model. Detailed parametric studies have been carried out to reveal the influences of CNTs volume fraction, CNTs distribution, CNTs orientation, dimension ratios and curvature on the free vibration responses of the doubly curved laminated FG-CNTRC panels.
\end{abstract}

Keywords: free vibration analysis; doubly-curved shell and panel; nano-composites; functionally graded carbon nanotube-reinforced composite (FG-CNTRC); four-variable refined shell theory

\section{Introduction}

Functionally graded carbon nanotube-reinforced composites were first proposed by Shen [1] and have been widely accepted as a new advanced material. In functionally graded carbon nanotube-reinforced composite (FG-CNTRC) structures, the CNTs are assumed to be distributed and functionally graded with certain rules along the desired direction to improve the mechanical properties of the structures. Due to the curvature effect, doubly curved shell structures possess increased structural stiffness as compared to flat ones. Therefore, doubly curved shells are often employed to fabricate structural elements of modern constructions made of advanced materials in various engineering disciplines such as aerospace, civil, marine and mechanical engineering. It is thus significant and very meaningful to explore the mechanical response of doubly curved shells made of laminated FG-CNTRC.

Due to its simplicity and effectiveness, the equivalent single-layer model is used for multi-layer composite materials. Among the equivalent single layer models, the model based on the classical theory (CPT) [2] only provides accurate results for the thin shell because it completely neglects the effect of shear deformation. To overcome the limitations of CPT, the model based on the first-order shear deformation theory (FSDT) [3] takes into account the shear deformation effects and provides relatively accurate results for both thin and moderately thick shells, but it has to use shear correction 
factor. Therefore, the model based on the higher-order shear deformation theory (HSDT) [4-6] is often desirable. However, it is not convenient to use HSDT because the equations of motions based on HSDT are complicated and difficult to solve. Therefore, the development of simple HSDT is needed. In addition to these, a four-variable deformation theory [7-11] has been developed and applied recently. In this theory model, the transverse shear stresses are satisfied to be parabolic and to be zero on free surfaces. Furthermore, it has only four unknowns, thus the governing equations can be reduced to four.

Based on the above-mentioned theories, various studies have been done to investigate the bending, buckling and vibration responses of FG-CNTRC shells and panels. Using the third-order shear deformation theory, Mehrabadi and Aragh [12] investigated static behavior of FG-CNTRC cylindrical shells. Aragh et al. [13] and Yas et al. [14] studied free vibration of FG-CNTRC cylindrical panels. Alibeigloo [15] analyzed the free vibration behavior of the FG-CNTRC cylindrical panel embedded in piezoelectric layers based on the three-dimensional theory of elasticity and the state-space technique. Lei et al. [16] presented the first-known dynamic stability of FG-CNTRC cylindrical panels under static and periodic axial force. Rasool el al. [17] analyzed the stress wave propagation of FG-CNTRC cylinders subjected to an impact load by using an element-free method. In [18], Shen and Zhang investigated thermal post-buckling of FG-CNTRC cylindrical shells subjected to a uniform temperature rise. Based on a HSDT with a von Kármán-type of kinematic nonlinearity, Shen [19] presented the thermal post-buckling and torsional post-buckling of FG-CNTRC cylindrical shells. Furthermore, Shen and Xiang also performed research on nonlinear vibration [20], and post-buckling [21] behavior of FG-CNTRC cylindrical shells in the thermal environment. A post-buckling analysis of FG-CNTRC cylindrical panels subjected to axial compression was also presented by Liew et al. [22]. In this study, Liew et al. used a meshless approach and arc-length method combined with the modified Newton-Raphson method to trace the post-buckling path. Using the element-free kp-Ritz method, Lei et al. [23] investigated free vibration of FG-CNTRC rotating cylindrical panels. Based on the generalized differential quadrature method (GDQM)and the finite element (FE) method, Tornabene et al. [24] and Thomas et al. [25], respectively, investigated free vibration of FG-CNT-reinforced laminated composite doubly curved shells.

The purpose of this paper is to develop a new four-variable refined shell theory for free vibration analysis of multi-layered functionally graded carbon nanotube-reinforced composite doubly curved panels. The present theory has only four unknowns but it satisfies the stress-free boundary conditions on the top and bottom surface without using shear correction factors. The distribution of the carbon nanotube (CNT) through the thickness of each layer may be functionally graded or uniformly distributed. The resultant eigenvalue system is solved to obtain the frequencies and mode shapes of the anti-symmetric, cross-ply laminated panels by Navier solution. The accuracy of the presented formulation is investigated by comparing the obtained natural frequencies with existing results in the literature. Also, a novelty parameter study of the laminated FG-CNTRC doubly-curved panels of which the geometrical parameters, CNTs distributions, the volume fraction of CNTs, as well as the number of layers are also reported in detail.

\section{Theoretical Formulations}

\subsection{Description of the Model}

As shown in Figure 1, a doubly curved FG-CNTRC shell panel in the orthogonal curvilinear coordinate system $(x, y, z)$ is considered as the modal analysis. The panel has curvilinear length $a$ in the $x$-direction, curvilinear width $b$ in the $y$-direction, thickness $h$ in the $z$-direction. In the middle surface of the panel, the principal radii of curvature, denoted by $R_{x}$ and $R_{y}$, are assumed as constants. This results in unit Lamé parameters. Here, four special kinds of the doubly curved shell panels are investigated such as plate (PLA, $\left.R_{x}=R_{y}=\infty\right)$, cylindrical (CYL) panel $\left(R_{x}=R\right.$ and $\left.R_{y}=\infty\right)$, spherical (SPH) panel $\left(R_{x}=R_{y}\right)$, and hyperbolic paraboloid (HPR) panel $\left(R_{x}=-R_{y}\right)$. 


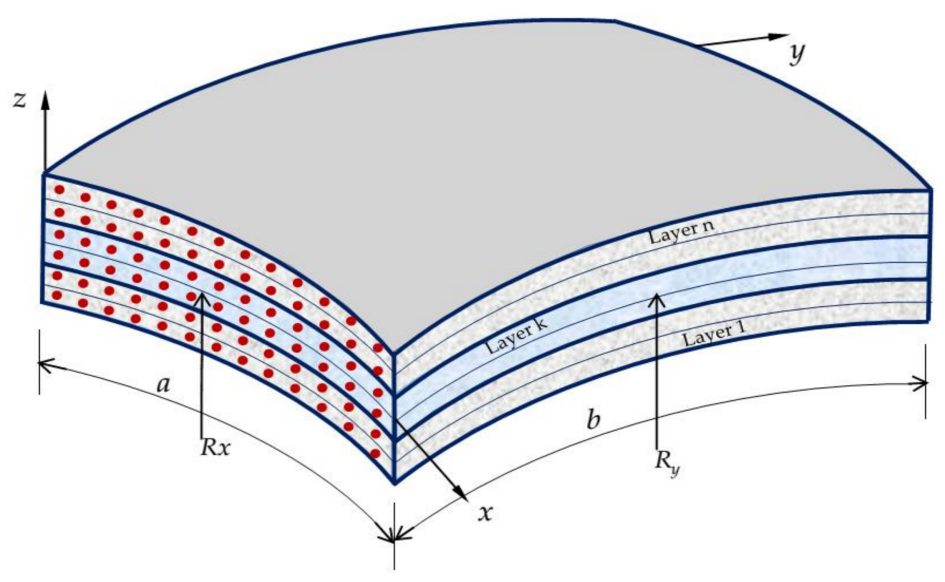

Figure 1. Schematic of the laminated functionally graded carbon nanotube-reinforced composite (FG-CNTRC) doubly curved panel.

\subsection{Material Properties of Functionally Graded Carbon Nanotube-Reinforced Composite}

In the present study, the lamina is assumed to be perfectly bonded at layer interfaces. As shown in Figure 2, five types of functionally graded distributions of CNTs in each layer are taken into consideration, named as UD, FG-A, FG-V, FG-X and FG-O.

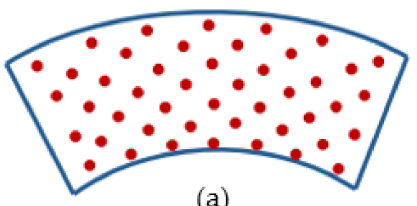

(a)

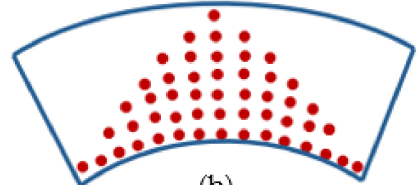

(b)

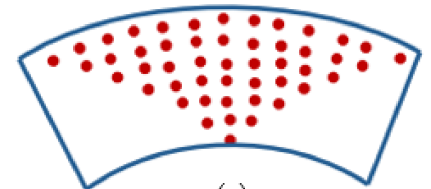

(c)

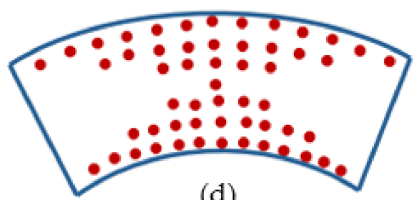

(d)

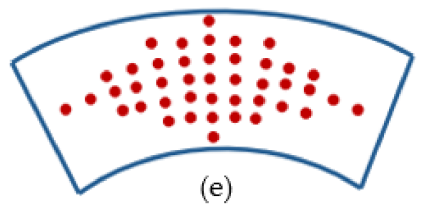

Figure 2. Configurations of the FG-CNTRC panels: (a) UD; (b) FG-A; (c) FG-V; (d) FG-X; (e) FG-O.

For these cases, the CNT volume fractions are given as [26]:

$$
\begin{aligned}
& U D: V_{C N T}(z)=V_{C N T}^{*} ; \\
& F G-V: V_{C N T}(z)=2 V_{C N T}^{*} \frac{z-z_{k}}{z_{k+1}-z_{k}} ; \\
& F G-A: V_{C N T}(z)=2 V_{C N T}^{*} \frac{z_{k+1}-z}{z_{k+1}-z_{k}} ; \\
& F G-O: V_{C N T}(z)=2 V_{C N T}^{*}\left(1-\frac{\left|2 z-z_{k}-z_{k+1}\right|}{z_{k+1}-z_{k}}\right) ; \\
& F G-X: V_{C N T}(z)=2 V_{C N T}^{*}\left(\frac{\left|2 z-z_{k}-z_{k+1}\right|}{z_{k+1}-z_{k}}\right)
\end{aligned}
$$

where $z_{k}$ and $z_{k+1}$ are the coordinates of the $k$-th layer to the reference plane $(z=0) . V_{C N T}^{*}$ is the given volume fraction of CNTs and can be calculated as:

$$
V_{C N T}^{*}=\frac{w_{C N T}}{w_{C N T}+\left(\rho^{C N T} / \rho^{m}\right)-\left(\rho^{C N T} / \rho^{m}\right) w_{C N T}}
$$


in which, $w_{C N T}$ is the mass fraction of the carbon nanotube, $\rho^{m}$ and $\rho^{C N T}$ are mass densities of the matrix and the CNT, respectively. The effective material properties of FG-CNTRC of each layer can be expressed by the extended rule of the mixture as follows [27]:

$$
\begin{aligned}
& E_{11}(z)=\eta_{1} V_{C N T}(z) E_{11}^{C N T}+V_{m}(z) E^{m} \\
& \frac{\eta_{2}}{E_{22}(z)}=\frac{V_{C N T}(z)}{E_{22}^{C N T}}+\frac{V_{m}(z)}{E^{m}} \\
& \frac{\eta_{3}}{G_{12}(z)}=\frac{V_{C N T}(z)}{G_{12}^{C N T}}+\frac{V_{m}(z)}{G^{m}} \\
& \rho(z)=V_{C N T}(z) \rho^{C N T}+V_{m}(z) \rho^{m} \\
& v_{12}=V_{C N T}^{*} v_{12}^{C N T}+V_{m}(z) v^{m}
\end{aligned}
$$

where $E_{11}^{C N T}, E_{22}^{C N T}, E^{m}$ and $G_{12}^{C N T}, G^{m}$ are the Young's moduli and shear modulus of CNT and matrix; $\eta_{1}, \eta_{2}$ and $\eta_{3}$ are $\mathrm{CNT} /$ matrix efficiency parameters; $V_{\mathrm{CNT}}(z)$ and $V_{m}(z)$ are volume fractions of CNT and matrix, and are related by $V_{C N T}(z)+V_{m}(z)=1 ; v_{12}^{C N T}$ and $v^{m}$ are Poisson's ratio of CNT and matrix.

\subsection{Kinematic Relations}

This work aims to establish a new shear deformation shell theory. The main idea of the present theory comes from the four-variable refined theory $[8,9,11,28,29]$. According to assumptions of various four-variable refined theories, the transverse displacement $w$ is partitioned into the bending component $w_{b}$ and shear component $w_{s}$, the in-plane displacements $u$ and $v$ are also partitioned into the extension component $u_{0}, v_{0}$, the bending component $u_{b}, v_{b}$, and shear component $u_{s}, v_{s}$. Therefore, the displacement field in the doubly curved shell space can be expressed as follows:

$$
\begin{aligned}
& u(x, y, z, t)=\left(1+\frac{z}{R_{x}}\right) u_{0}(x, y, t)-z \frac{\partial w_{b}(x, y, t)}{\partial x}-f(z) \frac{\partial w_{s}(x, y, t)}{\partial x} \\
& v(x, y, z, t)=\left(1+\frac{z}{R_{y}}\right) v_{0}(x, y, t)-z \frac{\partial w_{b}(x, y, t)}{\partial y}-f(z) \frac{\partial w_{s}(x, y, t)}{\partial y} \\
& w(x, y, z, t)=w_{b}(x, y, t)+w_{s}(x, y, t)
\end{aligned}
$$

where $u_{0}, v_{0}$ denote the displacements along $x$ and $y$ coordinate directions of the corresponding point on the reference surface; $w_{b}$ and $w_{s}$ are the bending and shear components of the transverse displacement, respectively; $f(z)$ represents shape function determining the distribution of the transverse shear strains and stresses along the thickness. By the same methodology, in the previous study [29], we proposed a new shape function $f(z)$ as follows:

$$
f(z)=z\left[-\frac{1}{8}+\frac{3}{2}\left(\frac{z}{h}\right)^{2}\right]
$$

Detail steps to construct this shape function for shell panels are listed in Appendix A.

The strains associated with the displacement field in Equation (4) are:

$$
\begin{aligned}
& \varepsilon_{x x}=\frac{1}{1+z / R_{x}}\left[\varepsilon_{x}^{0}+z \kappa_{x}^{b}+f(z) \kappa_{x}^{s}\right] ; \\
& \varepsilon_{y y}=\frac{1}{1+z / R_{y}}\left[\varepsilon_{y}^{0}+z \kappa_{y}^{b}+f(z) \kappa_{y}^{s}\right] ; \\
& \gamma_{x y}=\frac{1}{1+z / R_{x}}\left[\gamma_{x y}^{0}+z \kappa_{x y}^{b}+f(z) \kappa_{x y}^{s}\right]+\frac{1}{1+z / R_{y}}\left[\gamma_{y x}^{0}+z \kappa_{y x}^{b}+f(z) \kappa_{y x}^{s}\right] \\
& \gamma_{x z}=\frac{1}{1+z / R_{x}} g(z) \gamma_{x z}^{s} ; \\
& \gamma_{y z}=\frac{1}{1+z / R_{y}} g(z) \gamma_{y z}^{s}
\end{aligned}
$$


where:

$$
\begin{aligned}
& \varepsilon_{x}^{0}=\left(\frac{\partial u_{0}}{\partial x}+\frac{w_{b}}{R_{x}}+\frac{w_{s}}{R_{x}}\right) ; \quad \gamma_{x y}^{0}=\frac{\partial v_{0}}{\partial x} ; \\
& \varepsilon_{y}^{0}=\left(\frac{\partial v_{0}}{\partial y}+\frac{w_{b}}{R_{y}}+\frac{w_{s}}{R_{y}}\right) ; \quad \gamma_{y x}^{0}=\frac{\partial u_{0}}{\partial y} ; \\
& k_{x}^{b}=\left(\frac{1}{R_{x}} \frac{\partial u_{0}}{\partial x}-\frac{\partial w_{b}^{2}}{\partial x^{2}}\right) ; \kappa_{y}^{b}=\left(\frac{1}{R_{y}} \frac{\partial v_{0}}{\partial y}-\frac{\partial w_{b}^{2}}{\partial y^{2}}\right) ; \\
& \kappa_{x y}^{b}=\left(\frac{1}{R_{y}} \frac{\partial v_{0}}{\partial x}-\frac{\partial w_{b}^{2}}{\partial x \partial y}\right) ; \kappa_{y x}^{b}=\left(\frac{1}{R_{x}} \frac{\partial u_{0}}{\partial y}-\frac{\partial w_{b}^{2}}{\partial x \partial y}\right) ; \\
& k_{x}^{s}=-\frac{\partial^{2} w_{s}}{\partial x^{2}} ; k_{y}^{s}=-\frac{\partial^{2} w_{s}}{\partial y^{2}} ; \kappa_{x y}^{s}=\frac{\partial^{2} w_{s}}{\partial x \partial y} ; \kappa_{y x}^{s}=-\frac{\partial^{2} w_{s}}{\partial x \partial y} ; \\
& \gamma_{x z}=\frac{1}{1+z / R_{x}} g(z) \frac{\partial w_{s}}{\partial x} ; g(z)=\left(1-f^{\prime}(z)\right) ; \\
& \gamma_{y z}=\frac{1}{1+z / R_{x}} g(z) \frac{\partial w_{s}}{\partial y}
\end{aligned}
$$

The constitutive relation for an individual layer can be determined by the generalized Hooke's law, namely [30,31]:

$$
\left\{\begin{array}{c}
\sigma_{x x}^{k} \\
\sigma_{y y}^{k} \\
\tau_{y z}^{k} \\
\tau_{x z}^{k} \\
\tau_{x y}^{k}
\end{array}\right\}=\left[\begin{array}{ccccc}
\bar{Q}_{11}^{k} & \bar{Q}_{11}^{k} & 0 & 0 & \bar{Q}_{16}^{k} \\
\bar{Q}_{12}^{k} & \bar{Q}_{22}^{k} & 0 & 0 & \bar{Q}_{26}^{k} \\
0 & 0 & \bar{Q}_{44}^{k} & \bar{Q}_{45}^{k} & 0 \\
0 & 0 & \bar{Q}_{45}^{k} & \bar{Q}_{55}^{k} & 0 \\
\bar{Q}_{16}^{k} & \bar{Q}_{26}^{k} & 0 & 0 & \bar{Q}_{66}^{k}
\end{array}\right]\left\{\begin{array}{c}
\varepsilon_{x x} \\
\varepsilon_{y y} \\
\gamma_{y z} \\
\gamma_{x z} \\
\gamma_{x y}
\end{array}\right\}
$$

where $\bar{Q}_{i j}^{k}$ are the transformed material constraints expressed in terms of material constants:

$$
\begin{aligned}
& \bar{Q}_{11}^{k}=Q_{11} \cos ^{4} \theta^{k}+2\left(Q_{12}+2 Q_{66}\right) \sin ^{2} \theta^{k} \cos ^{2} \theta^{k}+Q_{22} \sin ^{4} \theta^{k} ; \\
& \bar{Q}_{12}^{k}=\left(Q_{11}+Q_{22}-4 Q_{66}\right) \sin ^{2} \theta^{k} \cos ^{2} \theta^{k}+Q_{12}\left(\sin ^{4} \theta^{k}+\cos ^{4} \theta^{k}\right) ; \\
& \bar{Q}_{22}^{k}=Q_{11} \sin ^{4} \theta^{k}+2\left(Q_{12}+2 Q_{66}\right) \sin ^{2} \theta^{k} \cos ^{2} \theta^{k}+Q_{22} \cos ^{4} \theta^{k} ; \\
& \bar{Q}_{16}^{k}=\left(Q_{11}-Q_{12}-2 Q_{66}\right) \sin \theta^{k} \cos ^{3} \theta^{k}+\left(Q_{12}-Q_{22}+2 Q_{66}\right) \sin ^{3} \theta^{k} \cos \theta^{k} ; \\
& \bar{Q}_{26}^{k}=\left(Q_{11}-Q_{12}-2 Q_{66}\right) \sin ^{3} \theta^{k} \cos \theta^{k}+\left(Q_{12}-Q_{22}+2 Q_{66}\right) \sin \theta^{k} \cos ^{3} \theta^{k} ; \\
& \bar{Q}_{66}^{k}=\left(Q_{11}+Q_{22}-2 Q_{12}-2 Q_{66}\right) \sin ^{2} \theta^{k} \cos ^{2} \theta^{k}+Q_{66}\left(\sin ^{4} \theta^{k}+\cos ^{4} \theta^{k}\right) ; \\
& \bar{Q}_{44}^{k}=Q_{44} \cos ^{2} \theta^{k}+Q_{55} \sin ^{2} \theta^{k} ; \\
& \bar{Q}_{45}^{k}=\left(Q_{55}-Q_{44}\right) \cos \theta^{k} \sin \theta^{k} ; \\
& \bar{Q}_{55}^{k}=Q_{55} \cos ^{2} \theta^{k}+Q_{44} \sin ^{2} \theta^{k} .
\end{aligned}
$$

in which, $Q_{i j}$ are the plane stress-reduced stiffnesses defined in terms of the engineering constants in the material axes of the layer. For each CNT layer:

$$
\begin{aligned}
& Q_{11}=\frac{E_{11}(z)}{1-v_{12} v_{21}} ; Q_{12}=\frac{v_{12} E_{22}(z)}{1-v_{12} v_{21}} ; Q_{22}=\frac{E_{22}(z)}{1-v_{12} v_{21}} ; \\
& Q_{44}=G_{23}(z) ; Q_{55}=G_{13}(z) ; Q_{66}=G_{12}(z)
\end{aligned}
$$




\subsection{Governing Equations}

Hamilton's principle is used herein to derive the equations of motion. In the absence of external forces, the principle can be stated in the analytical form as [32]:

$$
\int_{t_{1}}^{t_{2}}(\delta U-\delta K) d t=0
$$

where $\delta U$ is the variation of the strain energy, $\delta K$ is the variation of the kinetic energy, $t_{1}$ and $t_{2}$ are arbitrary time variables. The strain energy of the plate can be calculated as:

$$
\begin{aligned}
U= & \frac{1}{2} \int_{0}^{a} \int_{0}^{b} \int_{-h / 2}^{h / 2}\left(\sigma_{x x} \varepsilon_{x x}+\sigma_{y y} \varepsilon_{y y}+\tau_{x y} \gamma_{x y}+\tau_{x z} \gamma_{x z}+\tau_{y z} \gamma_{y z}\right)\left(1+\frac{z}{R_{x}}\right)\left(1+\frac{z}{R_{y}}\right) d z d y d x \\
= & \frac{1}{2} \int_{0}^{a} \int_{0}^{b}\left(N_{x x} \varepsilon_{x x}^{0}+N_{y y} \varepsilon_{y y}^{0}+N_{x y} \gamma_{x y}^{0}+N_{y x} \gamma_{y x}^{0}+M_{x x}^{b} \kappa_{x x}^{b}+M_{y y}^{b} \kappa_{y y}^{b}+M_{x y}^{b} \kappa_{x y}^{b}+M_{y x}^{b} \kappa_{y x}^{b}+\right. \\
& \left.M_{x x}^{s} \kappa_{x x}^{s}+M_{y y}^{s} \kappa_{y y}^{s}+M_{x y}^{s} \kappa_{x y}^{s}+M_{y x}^{s} \kappa_{y x}^{s}+Q_{y s} \gamma_{y z}^{s}+Q_{x s} \gamma_{x z}^{s}\right) d x d y
\end{aligned}
$$

where stress resultants $(N, M$ and $Q)$ are defined by:

$$
\begin{aligned}
& \left\{\begin{array}{l}
N_{x x} \\
N_{x y} \\
Q_{x s}
\end{array}\right\}=\sum_{k=1}^{n} \int_{z_{k}}^{z_{k+1}}\left(1+\frac{z}{R_{y}}\right)\left\{\begin{array}{c}
\sigma_{x x}^{k} \\
\sigma_{x y}^{k} \\
\tau_{x z}^{k}
\end{array}\right\} d z ;\left\{\begin{array}{c}
N_{y y} \\
N_{y x} \\
Q_{y s}
\end{array}\right\}=\sum_{k=1}^{n} \int_{z_{k}}^{z_{k+1}}\left(1+\frac{z}{R_{x}}\right)\left\{\begin{array}{c}
\sigma_{y y}^{k} \\
\sigma_{y x}^{k} \\
\tau_{y z}^{k}
\end{array}\right\} d z ; \\
& \left\{\begin{array}{l}
M_{x x}^{b} \\
M_{x y}^{b}
\end{array}\right\}=\sum_{k=1}^{n} \int_{z_{k}}^{z_{k+1}}\left(1+\frac{z}{R_{y}}\right)\left\{\begin{array}{c}
\sigma_{x x}^{k} \\
\sigma_{x y}^{k}
\end{array}\right\} z d z ;\left\{\begin{array}{l}
M_{y y}^{b} \\
M_{y x}^{b}
\end{array}\right\}=\sum_{k=1}^{n} \int_{z_{k}}^{z_{k+1}}\left(1+\frac{z}{R_{x}}\right)\left\{\begin{array}{c}
\sigma_{y y}^{k} \\
\sigma_{y x}^{k}
\end{array}\right\} z d z ; \\
& \left\{\begin{array}{l}
M_{x x}^{s} \\
M_{x y}^{s}
\end{array}\right\}=\sum_{k=1}^{n} \int_{z_{k}}^{z_{k+1}}\left(1+\frac{z}{R_{y}}\right)\left\{\begin{array}{c}
\sigma_{x x}^{k} \\
\sigma_{x y}^{k}
\end{array}\right\} f(z) d z ;\left\{\begin{array}{c}
M_{y y}^{s} \\
M_{y x}^{s}
\end{array}\right\}=\sum_{k=1}^{n} \int_{z_{k}}^{z_{k+1}}\left(1+\frac{z}{R_{x}}\right)\left\{\begin{array}{c}
\sigma_{y y}^{k} \\
\sigma_{y x}^{k}
\end{array}\right\} f(z) d z .
\end{aligned}
$$

Based on the constitutive relations (8), strain-displacement relation (6) and displacement field (4), the force and moment resultants can be rewritten in terms of displacement components as:

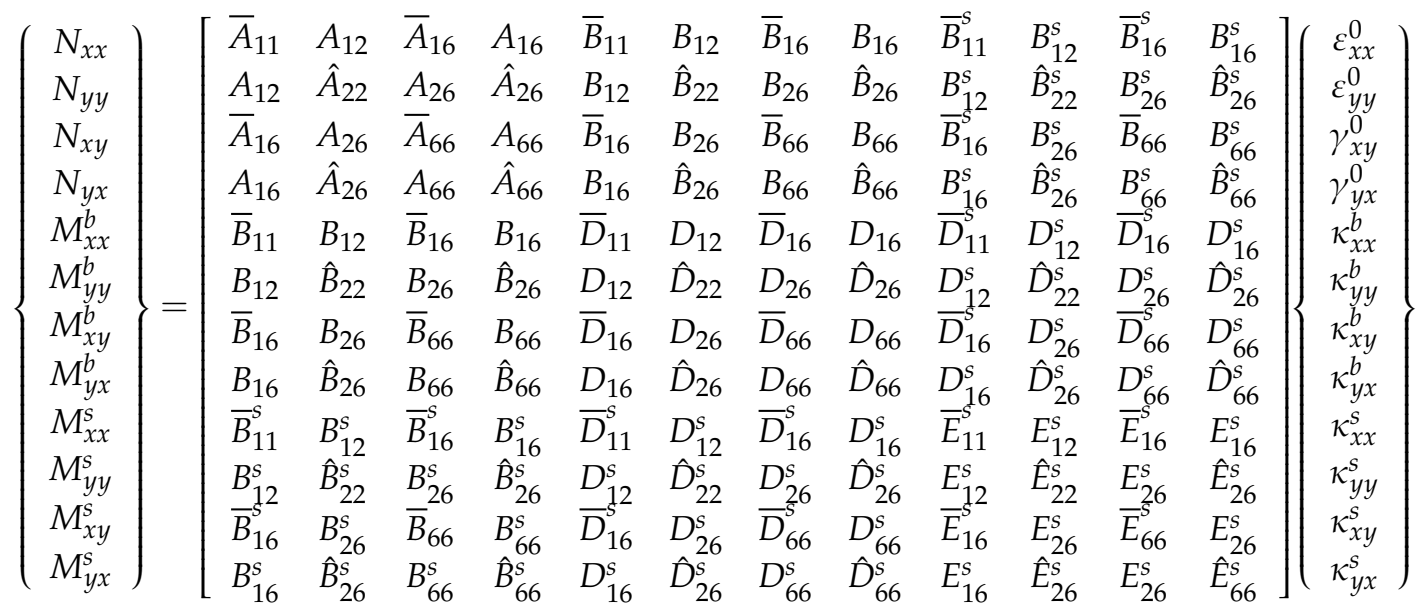

$$
\begin{aligned}
& \left\{\begin{array}{l}
Q_{y s} \\
Q_{x s}
\end{array}\right\}=\left[\begin{array}{cc}
\hat{A}_{44}^{s} & A_{45}^{s} \\
A_{45}^{s} & \bar{A}_{55}^{s}
\end{array}\right]\left\{\begin{array}{c}
\gamma_{y z}^{s} \\
\gamma_{x z}^{s}
\end{array}\right\}
\end{aligned}
$$


in which:

$$
\begin{aligned}
& \left\{A_{i j}, B_{i j}, D_{i j}, B_{i j}^{s}, D_{i j^{\prime}}^{s} A_{i j}^{s}\right\}=\sum_{1}^{N} \int_{z_{k}}^{z_{+1}} \bar{Q}_{i j}^{(k)}\left\{1, z, z^{2}, f(z), z f(z), g^{2}(z)\right\} d z \\
& \left\{\bar{A}_{i j}, \bar{B}_{i j}, \bar{D}_{i j}, \bar{B}_{i j}^{s}, \bar{D}_{i j}^{s}, \bar{A}_{i j}^{s}\right\}=\left\{A_{i j x}, B_{i j x}, D_{i j x}, B_{i j x^{\prime}}^{s} D_{i j x^{\prime}}^{s}, A_{i j x}^{s}\right\}+\frac{\left\{B_{i j x}, D_{i j x}, E_{i j x}, D_{i j x^{\prime}}^{s}, E_{i j x^{\prime}}^{s} A A_{i j x}^{s}\right\}}{R_{y}} ; \\
& \left\{A_{i j x}, B_{i j x}, D_{i j x}, E_{i j x}, B_{i j x^{\prime}}^{s} D_{i j x^{\prime}}^{s} E_{i j x^{\prime}}^{s} A_{i j x^{\prime}}^{s} A A_{i j x}^{s}\right\}= \\
& \sum_{1}^{N} \int_{z_{k}}^{z_{+1}} \bar{Q}_{i j}^{(k)} \frac{\left\{1, z, z^{2}, z^{3}, f(z), z f(z), z^{2} f(z), g(z), z g(z)\right\}}{1+z / R_{x}} d z \\
& \left\{\hat{A}_{i j}, \hat{B}_{i j}, \hat{D}_{i j}, \hat{B}_{i j}^{s}, \hat{D}_{i j}^{s}, \hat{A}_{i j}^{s}\right\}=\left\{A_{i j y}, B_{i j y}, D_{i j y}, B_{i j y^{\prime}}^{s} D_{i j y^{\prime}}^{s} A_{i j y}^{s}\right\}+\frac{\left\{B_{i j y}, D_{i j y}, E_{i j y}, D_{i j y^{\prime}}^{s} E_{i j y^{\prime}}^{s} A A_{i j y}^{s}\right\}}{R_{x}} \\
& \left\{A_{i j y}, B_{i j y}, D_{i j y}, E_{i j y}, B_{i j y^{\prime}}^{s} D_{i j y^{\prime}}^{s} E_{i j y^{\prime}}^{s} A_{i j y^{\prime}}^{s} A A_{i j y}^{s}\right\} \\
& =\sum_{1}^{N} \int_{z_{k}}^{z_{+1}} \bar{Q}_{i j}^{(k)} \frac{\left\{1, z, z^{2}, z^{3}, f(z), z f(z), z^{2} f(z), g(z), z g(z)\right\}}{1+z / R_{y}} d z
\end{aligned}
$$

The variation of the kinetic energy of the panel can be written as:

$$
\begin{aligned}
K= & \frac{1}{2} \int_{0}^{a} \int_{0}^{b} \int_{h / 2}^{h / 2} \rho(z)\left(\dot{u}^{2}+\dot{v}^{2}+\dot{w}^{2}\right)\left(1+\frac{z}{R_{x}}\right)\left(1+\frac{z}{R_{y}}\right) d z d y d x \\
= & \frac{1}{2} \int_{0}^{a} \int_{0}^{b}\left(\left(\bar{I}_{0} \dot{u}_{0}+\bar{I}_{2} \dot{\phi}_{x b}^{2}+\bar{K}_{1} \dot{\phi}_{x \mathrm{~s}}^{2}+2 \bar{I}_{1} \dot{u}_{0} \dot{\phi}_{x b}+2 \bar{J}_{1} \dot{u}_{0} \dot{\phi}_{x \mathrm{~s}}+2 \bar{J}_{2} \dot{\phi}_{x b} \dot{\phi}_{x \mathrm{~s}}+\bar{I}_{0} \dot{v}_{0}^{2}+\bar{I}_{2} \dot{\phi}_{y b}^{2}\right.\right. \\
& \left.+\bar{K}_{1} \dot{\phi}_{y s}^{2}+2 \bar{I}_{1} \dot{v}_{0} \dot{\phi}_{y b}+2 \bar{J}_{1} \dot{v}_{0} \dot{\phi}_{y s}+2 \bar{J}_{2} \dot{\phi}_{y b} \dot{\phi}_{y s}+\bar{I}_{0}\left(\dot{w}_{b}^{2}+\dot{w}_{2}^{s}+2 \dot{w}_{b} \dot{w}_{s}\right)\right) d y d x
\end{aligned}
$$

where:

$$
\phi_{x b}=\left(\frac{u_{0}}{R_{x}}-\frac{\partial w_{b}}{\partial x}\right) ; \phi_{x s}=-\frac{\partial w_{s}}{\partial x} ; \phi_{y b}=\left(\frac{v_{0}}{R_{y}}-\frac{\partial w_{b}}{\partial y}\right) ; \phi_{y s}=-\frac{\partial w_{s}}{\partial y}
$$

and $\rho(z)$ is the mass density, and the mass moments of inertia $\bar{I}_{i}(i=0,1,2)$ are defined as $[30,33]$ :

$$
\begin{aligned}
& \bar{I}_{i}=I_{i}+I_{i+1}\left(\frac{1}{R_{x}}+\frac{1}{R_{y}}\right)+\frac{I_{i+2}}{R_{x} R_{y}} ; \\
& \left\{I_{0}, I_{1}, I_{2}, I_{3}\right\}=\sum_{k=1}^{N} \int_{z_{k}}^{z_{+1}} \rho(z)\left\{1, z, z^{2}, z^{3}\right\} d z \\
& \bar{J}_{i}=f(z) \bar{I}_{i-1} ; \bar{K}_{1}=f^{2}(z) \bar{I}_{0}
\end{aligned}
$$

Substituting the expressions of $U$ and $K$ from Equation (12) and Equation (17) into Equation (11), and by performing some mathematical manipulations, the equations of motion of the shell panel are obtained as follows:

$$
\begin{aligned}
& 0=-\int_{A}\left[\begin{array}{c}
\left.\left.\left[\begin{array}{c}
\frac{\partial N_{x x}}{\partial x}+\frac{\partial N_{y x}}{\partial y}+\frac{Q_{x b}}{R_{x}}-\bar{I}_{0} \ddot{u}_{0}-\bar{I}_{1}\left(\frac{\ddot{u}_{0}}{R_{x}}-\frac{\partial \ddot{w}_{b}}{\partial x}\right)+\bar{J}_{1} \frac{\partial \ddot{w}_{s}}{\partial x} \\
{\left[\frac{\partial N_{y y}}{\partial y}+\frac{\partial N_{y x}}{\partial x}+\frac{Q_{y b}}{R_{y}}-\bar{I}_{0} \ddot{v}_{0}-\bar{I}_{1}\left(\frac{\ddot{w}_{0}}{R_{y}}-\frac{\partial \ddot{w}_{b}}{\partial y}\right)+\bar{J}_{1} \frac{\partial \ddot{w}_{s}}{\partial y}\right.}
\end{array}\right] \begin{array}{l}
\delta v_{0} \\
{\left[-\frac{\partial N_{x x}}{R_{x}}-\frac{\partial N_{y y}}{R_{y}}+\frac{\partial Q_{x b}}{\partial x}+\frac{\partial Q_{y b}}{\partial y}-\bar{I}_{0}\left(\ddot{w}_{b}+\ddot{w}_{s}\right)\right.} \\
-\frac{\partial N_{x x}}{R_{x}}-\frac{\partial N_{y y}}{R_{y}}+\frac{\partial Q_{x s}}{\partial x}+\frac{\partial Q_{y s}}{\partial y}-\bar{I}_{0}\left(\ddot{w}_{b}+\ddot{w}_{s}\right)
\end{array}\right]\right) \\
\delta w_{s}
\end{array}\right] d A \\
& +\int_{0}^{b}\left[\Gamma_{x}\right]_{0}^{a} d y+\int_{0}^{a}\left[\Gamma_{y}\right]_{0}^{b} d x
\end{aligned}
$$


where:

$$
\begin{aligned}
& Q_{x b}=\frac{\partial M_{x x}^{b}}{\partial x}+\frac{\partial M_{y x}^{b}}{\partial y}-\left(\bar{I}_{1}+\frac{\bar{I}_{2}}{R_{x}}\right) \ddot{u}_{0}+\bar{I}_{2} \frac{\partial \ddot{w}_{b}}{\partial_{x}}+\bar{J}_{2} \frac{\partial \ddot{w}_{s}}{\partial x} \\
& Q_{y b}=\frac{\partial M_{y y}^{b}}{\partial y}+\frac{\partial M_{x y}^{b}}{\partial x}-\left(\bar{I}_{1}+\frac{\bar{I}_{2}}{R_{y}}\right) \ddot{v}_{0}+\bar{I}_{2} \frac{\partial \ddot{w}_{b}}{\partial y}+\bar{J}_{2} \frac{\partial \ddot{w}_{s}}{\partial y} \\
& \bar{Q}_{x s}=\frac{\partial M_{x x}^{s}}{\partial x}+\frac{\partial M_{y x}^{s}}{\partial y}+Q_{x s}-\left(\bar{J}_{1}+\frac{\bar{J}_{2}}{R_{x}}\right) \ddot{u}_{0}+\bar{J}_{2} \frac{\partial \ddot{w}_{b}}{\partial x}+\bar{K}_{1} \frac{\partial \ddot{w}_{s}}{\partial_{x}} \\
& \bar{Q}_{y s}=\frac{\partial M_{y y}^{s}}{\partial y}+\frac{\partial M_{x y}^{s}}{\partial x}+Q_{y s}-\left(\bar{J}_{1}+\frac{\bar{J}_{2}}{R_{y}}\right) \ddot{v}_{0}+\bar{J}_{2} \frac{\partial \ddot{w}_{b}}{\partial_{x}}+\bar{K}_{1} \frac{\partial \ddot{w}_{s}}{\partial_{y}}
\end{aligned}
$$

and $\Gamma_{x}, \Gamma_{y}$ are boundary expressions:

$$
\begin{aligned}
& \Gamma_{x}=\bar{N}_{x x} \delta u_{0}+\bar{N}_{x y} \delta v_{0}+Q_{x b} \delta w_{b}+\bar{Q}_{x s} \delta w_{s}+M_{x x}^{b} \delta \widetilde{\phi}_{x b}+M_{x y}^{b} \delta \widetilde{\phi}_{y b}+M_{x x}^{s} \delta \phi_{x s}+M_{x y}^{s} \delta \phi_{y s} \\
& \Gamma_{y}=\bar{N}_{y y} \delta v_{0}+\bar{N}_{y x} \delta u_{0}+Q_{y b} \delta w_{b}+\bar{Q}_{y s} \delta w_{s}+M_{y y}^{b} \delta \widetilde{\phi}_{y b}+M_{y x}^{b} \delta \widetilde{\phi}_{x b}+M_{y y}^{s} \delta \phi_{y s}+M_{y x}^{s} \delta \phi_{x s}
\end{aligned}
$$

in which:

$$
\begin{aligned}
& \bar{N}_{x x}=\left(N_{x x}-\frac{M_{x x}^{b}}{R_{x}}\right) ; \bar{N}_{x y}=\left(N_{x y}-\frac{M_{x y}^{b}}{R_{y}}\right) ; \bar{N}_{y y}=\left(N_{y y}-\frac{M_{y y}^{b}}{R_{y}}\right) ; \bar{N}_{y x}=\left(N_{y x}-\frac{M_{y x}^{b}}{R_{x}}\right) ; \\
& \widetilde{\phi}_{x b}=-\frac{\partial w_{b}}{\partial x} ; \phi_{x s}=-\frac{\partial w_{s}}{\partial x} ; \widetilde{\phi}_{y b}=-\frac{\partial w_{b}}{\partial y} ; \phi_{y s}=-\frac{\partial w_{s}}{\partial y}
\end{aligned}
$$

By setting the coefficients of the virtual displacements $\delta u_{0}, \delta v_{0}, \delta w_{b}, \delta w_{s}$ to zeros, the governing equations are obtained as follows:

$$
\begin{aligned}
& \delta u_{0}: \frac{\partial N_{x x}}{\partial x}+\frac{\partial N_{y x}}{\partial y}+\frac{Q_{x b}}{R_{x}}=\bar{I}_{0} \ddot{u}_{0}+\bar{I}_{1}\left(\frac{\ddot{u}_{0}}{R_{x}}-\frac{\partial \ddot{w}_{b}}{\partial_{y}}\right)-\bar{J}_{1} \frac{\partial \ddot{w}_{s}}{\partial x} \\
& \delta v_{0}: \frac{\partial N_{y y}}{\partial y}+\frac{\partial N_{y x}}{\partial x}+\frac{Q_{y b}}{R_{y}}=\bar{I}_{0} \ddot{v}_{0}+\bar{I}_{1}\left(\frac{\ddot{w}_{0}}{R_{y}}-\frac{\partial \ddot{w}_{b}}{\partial_{y}}\right)-\bar{J}_{1} \frac{\partial \ddot{w}_{s}}{\partial y} \\
& \delta w_{b}: \frac{\partial N_{x x}}{R_{x}}+\frac{\partial N_{y y}}{R_{y}}-\frac{\partial Q_{x b}}{\partial x}-\frac{\partial Q_{y b}}{\partial y}=-\bar{I}_{0}\left(\ddot{w}_{b}+\ddot{w}_{s}\right) \\
& \delta w_{s}: \frac{\partial N_{x x}}{R_{x}}+\frac{\partial N_{y y}}{R_{y}}-\frac{\partial Q_{x s}}{\partial x}-\frac{\partial Q_{y s}}{\partial y}=-\bar{I}_{0}\left(\ddot{w}_{b}+\ddot{w}_{s}\right)
\end{aligned}
$$

\subsection{Solution Procedure}

The Navier method is employed to formulate the closed-form solution for vibration problems of simply supported anti-symmetric cross-ply laminated FG-CNTRC panels. The simply supported boundary conditions on all four edges can be considered as:

$$
\begin{aligned}
& v_{0}=w_{b}=w_{s}=w_{b, y}=w_{s, y}=N_{x x}=M_{x x}^{b}=M_{x x}^{s}=0 \text { at } x=0 \text { and } x=a \\
& u_{0}=w_{b}=w_{s}=w_{b, x}=w_{s, x}=N_{y y}=M_{y y}^{b}=M_{y y}^{s}=0 \text { at } y=0 \text { and } y=b
\end{aligned}
$$


These boundary conditions are exactly satisfied by the following double Fourier series forms:

$$
\begin{aligned}
& u(x, y, t)=\sum_{m=1}^{\infty} \sum_{n=1}^{\infty} U_{m n} e^{i \omega t} \cos \alpha_{m} x \sin \beta_{n} y ; \\
& v(x, y, t)=\sum_{m=1}^{\infty} \sum_{n=1}^{\infty} V_{m n} e^{i \omega t} \sin \alpha_{m} x \cos \beta_{n} y ; \\
& w_{b}(x, y, t)=\sum_{m=1}^{\infty} \sum_{n=1}^{\infty} W_{b m n} e^{i \omega t} \sin \alpha_{m} x \sin \beta_{n} y ; \\
& w_{s}(x, y, t)=\sum_{m=1}^{\infty} \sum_{n=1}^{\infty} W_{s m n} e^{i \omega t} \sin \alpha_{m} x \sin \beta_{n} y .
\end{aligned}
$$

where $\left(U_{m n}, V_{m n}, W_{b m n}, W_{s m n}\right)$ are unknown coefficients to be determined, $\omega$ is the circular frequency of vibration, and $i=\sqrt{-1}, \alpha_{m}=m \pi / a, \beta_{n}=n \pi / b$ and $m, n$ denote the number of haft-waves in the $x$ and $y$ directions, respectively.

Substituting the admissible displacement functions of Equation (27) into the equation of motion, Equation (20), one obtains the analytical solution in the following matrix form:

$$
\left(\left[\begin{array}{llll}
s_{11} & s_{12} & s_{13} & s_{14} \\
s_{12} & s_{22} & s_{23} & s_{24} \\
s_{13} & s_{23} & s_{33} & s_{34} \\
s_{14} & s_{24} & s_{34} & s_{44}
\end{array}\right]-\omega^{2}\left[\begin{array}{llll}
m_{11} & m_{12} & m_{13} & m_{14} \\
m_{12} & m_{22} & m_{23} & m_{24} \\
m_{13} & m_{23} & m_{33} & m_{34} \\
m_{14} & m_{24} & m_{34} & m_{44}
\end{array}\right]\right)\left\{\begin{array}{c}
U_{m n} \\
V_{m n} \\
W_{b m n} \\
W_{s m n}
\end{array}\right\}=\left\{\begin{array}{l}
0 \\
0 \\
0 \\
0
\end{array}\right\}
$$

where the matrix elements of Equation (28) are given in the Appendix B.

\section{Numerical Results and Discussions}

In this section, several examples are presented and discussed to verify the accuracy and efficiency of the proposed theory in free vibration analysis of simply supported FG-CNTRC doubly-curved panels. Furthermore, the effects of volume fraction of CNTs, distribution type of CNTs, number of layers, CNT fiber orientation and geometrical parameters on the natural frequencies of panels are also investigated in detail. The material properties for the matrix and CNT are given in Table 1 [34,35]. Also, the CNT efficiency parameters $\eta_{j}(j=1,2,3)$ associated with a given volume fraction $V_{C N T}^{*}$ are: $\eta_{1}=0.149$ and $\eta_{2}=\eta_{3}=0.934$ for the case of $V_{C N T}^{*}=0.11 ; \eta_{1}=0.150$ and $\eta_{2}=\eta_{3}=0.941$ for the case of $V_{C N T}^{*}=0.14 ; \eta_{1}=0.149$ and $\eta_{2}=\eta_{3}=1.381$ for the case of $V_{C N T}^{*}=0.17$.

Table 1. Material properties of carbon nanotube (CNT) and matrix materials.

\begin{tabular}{cc}
\hline CNT & Matrix \\
\hline$E_{11}^{C N T}=5.6466 \mathrm{TPa}$ & $E^{m}=2.1 \mathrm{GPa}$ \\
$E_{22}^{C N T}=7.0800 \mathrm{TPa}$ & $v^{m}=0.34$ \\
$G_{12}^{C N T}=1.9445 \mathrm{TPa}$ & $\rho^{m}=1150 \mathrm{~kg} / \mathrm{m}^{3}$ \\
$v_{12}^{C N T}=0.175$ & - \\
$\rho^{C N T}=1400 \mathrm{~kg} / \mathrm{m}^{3}$ & - \\
\hline
\end{tabular}

\subsection{Comparison Studies}

To verify the reliability and accuracy of the present model, several comparison studies were carried out with the results of the previous literature [34,35].

\section{Example 1: Free Vibration of the Simply Supported Doubly Curved FG-CNTRC Panels}

Free vibration of the simply supported doubly curved single-layered FG-CNTRC panels is further analyzed for the comparison of the results obtained from the present formulation with the existing results developed by Pouresmaeeli and Fazelzadeh [34] based on FSDT formulations. The geometrical dimensions of the panels are taken as $a / b=1$ and $a / h=20$. Values of material parameters are listed 
in Table 1. From the results presented in Table 2, it is observed that the values of the fundamental frequency for plates, spherical, cylindrical, and hyperbolic paraboloid panels have excellent agreement with the available data.

Table 2. Comparison of the non-dimensional frequencies $\bar{\omega}=\omega\left(a^{2} / h\right) \sqrt{\rho^{m} / E^{m}}$ of the simply supported doubly curved FG-CNTRC panels.

\begin{tabular}{|c|c|c|c|c|c|c|c|c|c|c|}
\hline \multirow{2}{*}{$a / R_{x}$} & \multirow{2}{*}{$b / R_{y}$} & \multirow{2}{*}{$V^{*} C N T$} & \multicolumn{2}{|c|}{ UD } & \multicolumn{2}{|c|}{ FG-V } & \multicolumn{2}{|c|}{ FG-X } & \multicolumn{2}{|c|}{ FG-O } \\
\hline & & & [34] & Present & [34] & Present & [34] & Present & [34] & Present \\
\hline \multirow{3}{*}{0.5} & \multirow{3}{*}{0.5} & 0.11 & 20.238 & 20.087 & 18.543 & 17.917 & 22.432 & 22.752 & 17.140 & 16.653 \\
\hline & & 0.14 & 21.655 & 21.700 & 19.779 & 19.184 & 23.997 & 24.642 & 18.267 & 17.790 \\
\hline & & 0.17 & 25.051 & 24.691 & 22.951 & 21.848 & 27.883 & 28.023 & 21.212 & 20.419 \\
\hline \multirow{3}{*}{0.5} & \multirow{3}{*}{-0.5} & 0.11 & 17.106 & 17.282 & 14.809 & 14.617 & 19.588 & 20.253 & 13.364 & 13.202 \\
\hline & & 0.14 & 18.626 & 19.005 & 16.181 & 16.065 & 21.225 & 22.203 & 14.610 & 14.493 \\
\hline & & 0.17 & 21.095 & 21.214 & 18.225 & 17.875 & 24.274 & 24.879 & 16.389 & 16.149 \\
\hline \multirow{3}{*}{0.5} & \multirow{3}{*}{0} & 0.11 & 18.126 & 18.210 & 16.060 & 15.698 & 20.548 & 21.120 & 14.553 & 14.297 \\
\hline & & 0.14 & 19.628 & 19.890 & 17.391 & 17.065 & 22.179 & 23.044 & 15.766 & 15.525 \\
\hline & & 0.17 & 22.380 & 22.328 & 19.799 & 19.111 & 25.488 & 25.925 & 17.903 & 17.472 \\
\hline \multirow{3}{*}{0} & \multirow{3}{*}{0} & 0.11 & 18.008 & 18.201 & 15.701 & 15.55 & 20.624 & 21.332 & 14.068 & 13.907 \\
\hline & & 0.14 & 19.608 & 20.016 & 17.147 & 17.089 & 22.349 & 23.391 & 15.378 & 15.265 \\
\hline & & 0.17 & 22.207 & 22.343 & 19.315 & 19.021 & 25.557 & 26.208 & 17.252 & 17.012 \\
\hline
\end{tabular}

\subsection{Parametric Studies}

In this section, some new results for free vibration of the anti-symmetric cross-ply laminated FG-CNTRC doubly curved shell panels are investigated with respect to FG-CNTRC parameters, curvature, $R_{x} / R_{y}$ ratio, aspect $a / b$ ratio, and number of layers. The material properties for the matrix and CNT are shown in Table 1.

\subsubsection{Effect of FG-CNTRC Parameters}

To understand the effect of FG-CNTRC parameters on the free vibration response of different shell panels, non-dimensional frequencies $\bar{\omega}$ of anti-symmetric cross-ply laminated FG-CNTRC doubly curved shell panels with different CNT distribution, CNT volume fraction, and number of CNT layers are examined.

It is observed from Table 3, that the FG-X panels have the highest value of frequency, whereas, the FG-O panels have the lowest one. Therefore, it can be concluded that the type of CNT distribution has a remarkable influence on the stiffness of the FG-CNTRC shell panels. In detail, the CNTs distributed close to the top and bottom surfaces of each FG-CNTRC layer are more efficient than those distributed near the mid-plane of each FG-CNTRC layer in increasing the stiffness of the laminated FG-CNTRC shell panels. This is compatible with conclusions in previous studies in the literature. According to the detailed results, the values of $\bar{\omega}$ can be increased by more than $24 \%$ with only $6 \%$ increasing CNT volume fraction $V_{C N T}^{*}$ for any other parameters. Thus, by adjusting a small amount of CNT volume, the desired stiffness of the FG-CNTRC panels can be achieved. Table 3 also reveals that the SHP panel has the highest value of $\bar{\omega}$ while the HPR panel has the lowest one. This is because HPR has both sagging and hogging curvature along the two directions, neutralizing the effect of each other, while SHP does not. Table 3, once again confirms the accuracy of the present model by comparing the non-dimensional frequencies of the FG-CNTRC plates with the results of Wang [35]. 
Table 3. Non-dimensional frequencies $\bar{\omega}$ of the simply supported FG-CNTRC doubly curved shell panels $(a / b=1 ; R / a=5, a / h=50)$.

\begin{tabular}{|c|c|c|c|c|c|c|c|c|c|c|c|}
\hline \multirow{3}{*}{\multicolumn{2}{|c|}{ Shape }} & \multirow{3}{*}{ CNT Distribution } & \multirow{2}{*}{\multicolumn{3}{|c|}{$\begin{array}{l}(0 / 90) \\
V_{C N T}^{*} \\
\end{array}$}} & \multirow{2}{*}{\multicolumn{3}{|c|}{$\frac{(0 / 90)_{2}}{V_{C N T}^{*}}$}} & \multirow{2}{*}{\multicolumn{3}{|c|}{$\begin{array}{l}(0 / 90)_{4} \\
V_{C N T}^{*}\end{array}$}} \\
\hline & & & & & & & & & & & \\
\hline & & & 0.11 & 0.14 & 0.17 & 0.11 & 0.14 & 0.17 & 0.11 & 0.14 & 0.17 \\
\hline \multirow{5}{*}{\multicolumn{2}{|c|}{ CYL }} & UD & 12.854 & 13.841 & 15.937 & 18.658 & 20.596 & 23.032 & 19.829 & 21.941 & 24.467 \\
\hline & & FG-A & 11.383 & 12.181 & 14.177 & 18.367 & 20.295 & 22.700 & 19.739 & 21.856 & 24.378 \\
\hline & & FG-V & 12.216 & 12.969 & 15.137 & 18.624 & 20.528 & 22.998 & 19.858 & 21.963 & 24.516 \\
\hline & & FG-X & 14.442 & 15.713 & 17.937 & 19.084 & 21.089 & 23.582 & 20.062 & 22.212 & 24.776 \\
\hline & & FG-O & 11.067 & 11.720 & 13.753 & 18.241 & 20.121 & 22.528 & 19.610 & 21.694 & 24.207 \\
\hline \multirow{5}{*}{\multicolumn{2}{|c|}{$\mathrm{SPH}$}} & UD & 16.540 & 17.442 & 20.579 & 21.334 & 23.132 & 26.419 & 22.364 & 24.335 & 27.677 \\
\hline & & FG-A & 15.143 & 15.902 & 18.967 & 20.984 & 22.786 & 26.050 & 22.245 & 24.232 & 27.583 \\
\hline & & FG-V & 16.366 & 17.080 & 20.371 & 21.426 & 23.193 & 26.560 & 22.453 & 24.423 & 27.823 \\
\hline & & FG-X & 17.812 & 18.980 & 22.214 & 21.722 & 23.595 & 26.951 & 22.587 & 24.604 & 28.002 \\
\hline & & FG-O & 15.214 & 15.845 & 18.990 & 20.977 & 22.723 & 26.008 & 22.175 & 24.123 & 27.472 \\
\hline \multirow{5}{*}{\multicolumn{2}{|c|}{ HPR }} & UD & 11.295 & 12.340 & 13.969 & 17.583 & 19.576 & 21.671 & 18.806 & 20.969 & 23.171 \\
\hline & & FG-A & 10.085 & 10.900 & 12.474 & 17.407 & 19.374 & 21.459 & 18.768 & 20.928 & 23.133 \\
\hline & & FG-V & 10.085 & 10.900 & 12.474 & 17.407 & 19.374 & 21.459 & 18.768 & 20.928 & 23.133 \\
\hline & & FG-X & 13.057 & 14.384 & 16.174 & 18.023 & 20.080 & 22.229 & 19.042 & 21.240 & 23.474 \\
\hline & & FG-O & 9.219 & 9.907 & 11.409 & 17.141 & 19.075 & 21.128 & 18.574 & 20.708 & 22.889 \\
\hline \multirow{8}{*}{ PLATE } & Present & UD & 11.353 & 12.401 & 14.040 & 17.696 & 19.701 & 21.810 & 18.943 & 21.122 & 23.340 \\
\hline & [35] & & 11.348 & 12.395 & 14.035 & 17.714 & 19.726 & 21.831 & 18.958 & 21.142 & 23.358 \\
\hline & Present & FG-V & 10.138 & 10.956 & 12.541 & 17.519 & 19.498 & 21.597 & 18.906 & 21.081 & 23.302 \\
\hline & [35] & & 10.056 & 10.876 & 12.435 & 17.495 & 19.484 & 21.565 & 18.883 & 21.065 & 23.271 \\
\hline & Present & FG-X & 13.120 & 14.453 & 16.253 & 18.139 & 20.208 & 22.372 & 19.181 & 21.395 & 23.646 \\
\hline & 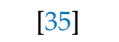 & & 13.064 & 14.396 & 16.180 & 17.975 & 20.032 & 22.165 & 18.995 & 21.193 & 23.411 \\
\hline & Present & FG-O & 9.270 & 9.960 & 11.472 & 17.251 & 19.197 & 21.264 & 18.710 & 20.859 & 23.057 \\
\hline & [35] & & 9.182 & 9.874 & 11.367 & 17.378 & 19.354 & 21.421 & 18.856 & 21.036 & 23.238 \\
\hline
\end{tabular}

\subsubsection{Effect of Curvature}

Two forms of doubly curved shell panels (SPH and HPR) with $a / b=1, a / h=20, R_{x}=R_{y}=R,(0 / 90)_{5}$, $V_{C N T}^{*}=0.17$ were considered, to study the effect of curvature on the non-dimensional frequencies $\bar{\omega}$. The results are shown in the Figure $3 a, b$. These figures indicate that at the small value of $R / a$, the SHP panels have a much higher non-dimensional frequency than HPR panels. The non-dimensional frequencies of the SHP panels decrease, while those of HPR panels increase with the increase of $R / a$ ratio from one to a specific value. After this value, the non-dimensional frequencies of both SHP and HPR panels have approximate values and seem to be unchanged.

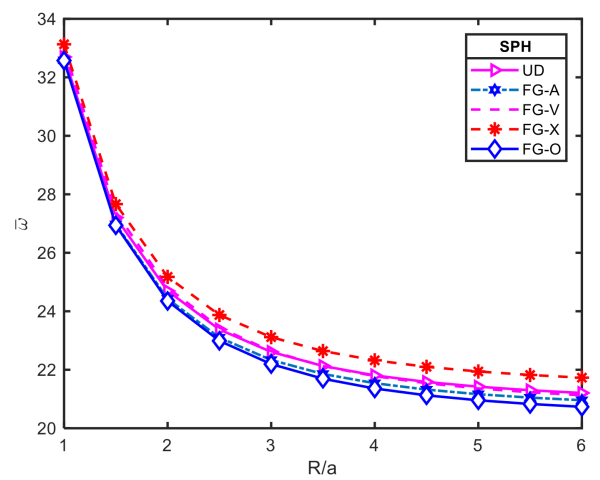

(a)

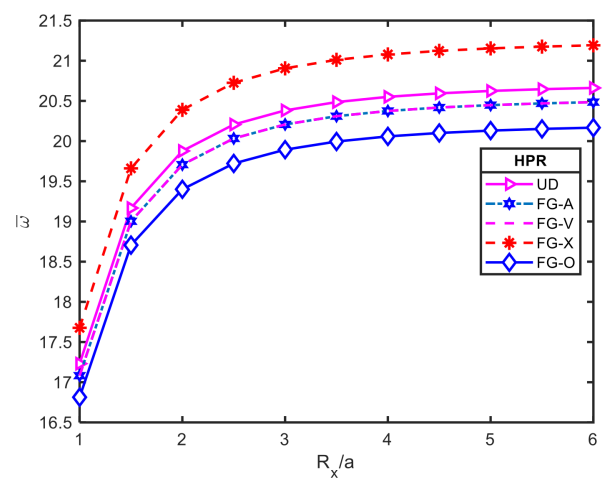

(b)

Figure 3. Effect of $R / a$ ratio on the frequency parameter $\bar{\omega}$ of FG-CNTRC shell panels. $(a / b=1, a / h=$ $\left.20, R_{x}=R_{y}=R,(0 / 90)_{5}, V_{C N T}^{*}=0.17\right):(\mathbf{a}) \mathrm{SPH}$ panel; (b) HPR panel. 


\subsubsection{Effect of Curvature Ratio}

The effect of curvature ratio $R_{x} / R_{y}$ on non-dimension frequency of the panels is investigated in this subsection. The geometrical dimensions of the panels are taken as $a / b=1, a / h=20, R_{x} / a=5$. It can be seen from Figure $4 a, b$, that the non-dimension frequencies of panels decrease with the increase of curvature ratio from -3 to -1 , and increase with the value of curvature ratio bigger than -1 for different numbers of layers and different CNT volume fractions. Moreover, the values of $\bar{\omega}$ are at minimum when $R_{x} / R_{y}=-1$ shows that the curvature effect can be suppressed if the shell panels have both negative and positive curvature.

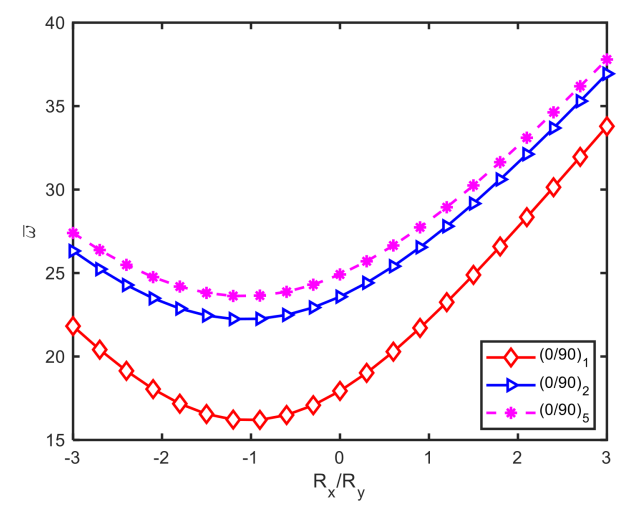

(a)

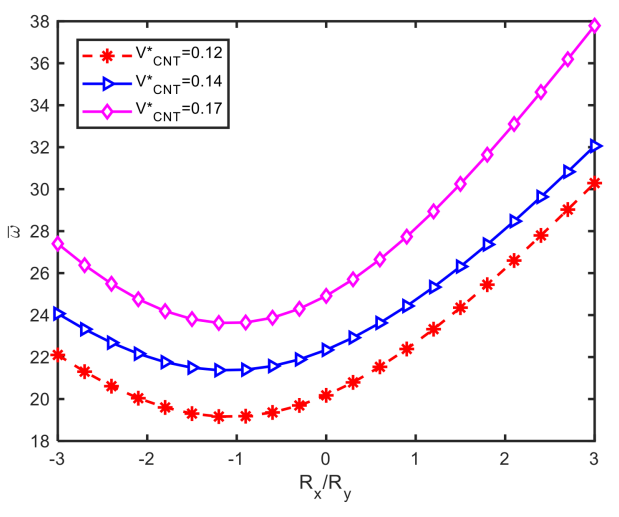

(b)

Figure 4. Effect of $R_{x} / R_{y}$ of FG-CNTRC shell panels $\left(a / b=1, a / h=20, R_{x} / a=5\right.$, FG-X): (a) For different number of layers, $V_{C N T}^{*}=0.17 ;(\mathbf{b})$ for different $C N T$ volume fractions.

\subsubsection{Effect of Thickness Ratio}

The SPH shell panel was chosen to study the effect of thickness on the free vibration response of the FG-CNTRC doubly curved shell panel. For this purpose, another non-dimensional frequency is defined as [34]:

$$
\begin{gathered}
\hat{\omega}=\omega a \sqrt{\frac{\rho^{m}}{E^{m}}} \\
P C F=\left(\frac{\hat{\omega}_{F G}-\hat{\omega}_{U D}}{\hat{\omega}_{U D}}\right) \times 100
\end{gathered}
$$

The effect of thickness ratio, $h / a$, on the non-dimensional frequency of the FG-CNTRC panels is shown in Figure 5. This figure indicates that with all types of CNT distribution, the panels become stiffer with the increase of the thickness ratio, as a result, the non-dimensional frequency of the FG-CNTRC panels increase. Besides, the influence of the thickness ratio, $h / a$, on the percentage change of frequency (PCF) of the SHP panel is depicted in Figure 5b. It is observed that FG-X panels show positive effectiveness while other FG-CNTRC panels show the negative effects concerning uniformly distribution (UD) panels. The highest percentage change of frequency of an FG-X panel and FG-O panel are about $14.5 \%$ and $-15.2 \%$, respectively. 


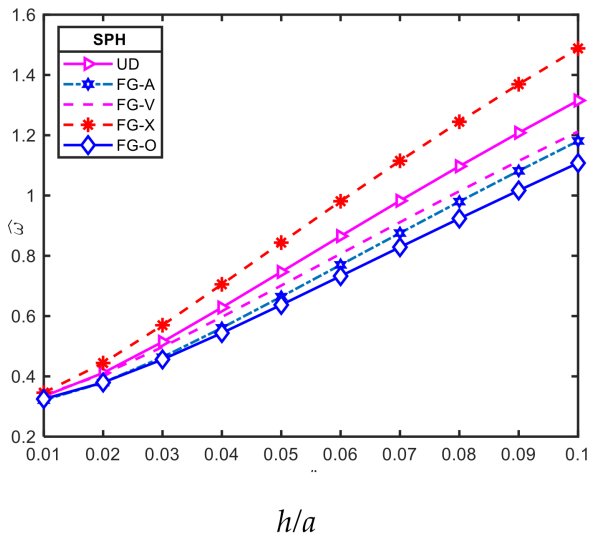

(a)

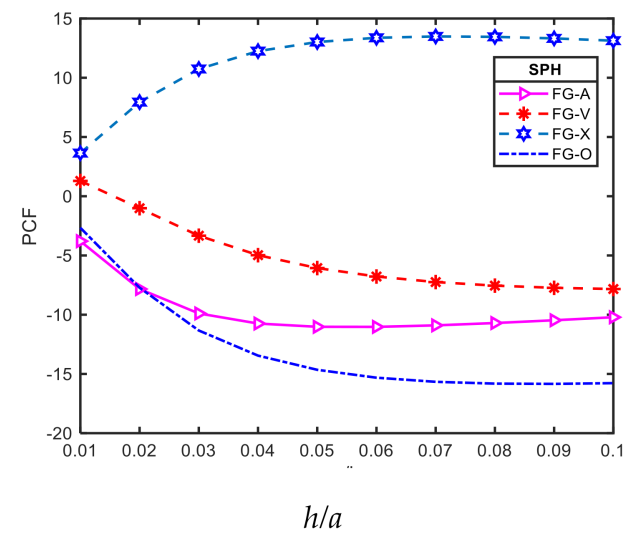

(b)

Figure 5. Effect of $h / a$ ratio on free vibration of FG-CNTRC shell panels $\left(\left(\mathrm{a} / \mathrm{b}=1 ; R_{x}=R_{y}=R\right.\right.$; $\left.V_{C N T}^{*}=0.17 ;(0 / 90)\right)$ : (a) For the frequency parameter $\hat{\omega}=\omega a \sqrt{\frac{\rho^{m}}{E^{m}}} ;(\mathbf{b})$ for the $(P C F)$.

\subsubsection{Effect of Aspect Ratio}

Figure $6 \mathrm{a}, \mathrm{b}$ show the effects of the aspect ratio $(a / b)$ on the vibration of FG-CNTRC. Here, we take $a / b=1 ; R_{x}=R_{y}=R ; R / a=5 ; V_{C N T}^{*}=0.17$ and $(0 / 90)$.

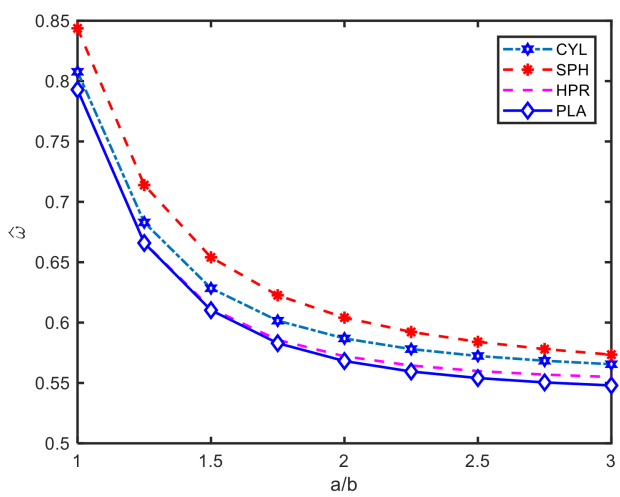

(a)

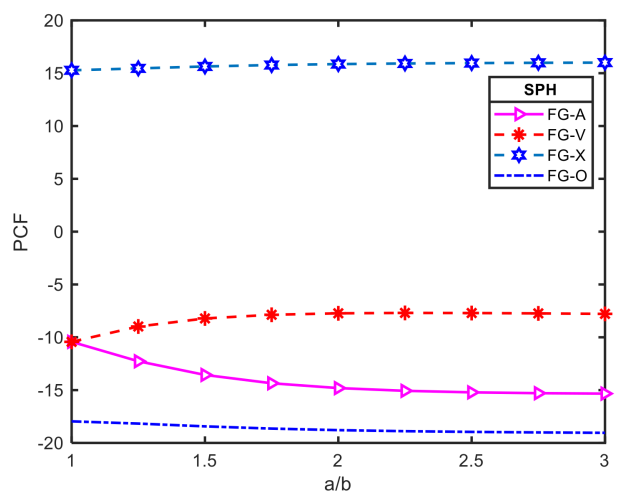

(b)

Figure 6. Effect of aspect ratio $(a / b)$ on free vibration of FG-CNTRC shell panels $\left(a / b=1 ; R_{x}=R_{y}=R\right.$; $\left.V_{C N T}^{*}=0.17 ;(0 / 90)\right)$ : (a) For the frequency parameter $\hat{\omega}=\omega a \sqrt{\frac{\rho^{m}}{E^{m}}} ;(\mathbf{b})$ For the percentage change of frequency (PCF).

Figure 6a reveals that the non-dimensional frequencies of all four types of doubly curved panels decrease uniformly by increasing aspect ratio. In other words, the stiffness of doubly curved panels will be reduced as the aspect ratio increases. Figure 6a states that the PCF of the FG-CNTRC panels remains unchanged with the increase of aspect ratio.

\subsubsection{Effect of Number of Layers}

The influence of number of layers ( $n$ is a couple of layers (0/90)) on $\hat{\omega}$, and PCF are depicted in Figure $7 \mathrm{a}, \mathrm{b}$, respectively. Here, the geometrical dimensions of the panels are taken as $a / b=1, a / h=20$, $R_{x}=R_{y}=R$, and $V_{C N T}^{*}=0.17, \mathrm{FG}-\mathrm{X},(0 / 90)_{\mathrm{n}}$. As the Figures show, with a fixed value of total thickness, the non-dimensional frequencies and the percentage change of frequency of laminated FG-CNTRC panels are strongly affected by the number of layers, changing from one layer to two layers. However, these two dimensionless parameters vary very slightly for the number of layers greater than three. This is compatible with the investigations of Reddy [31], for conventional fiber reinforced composites. 


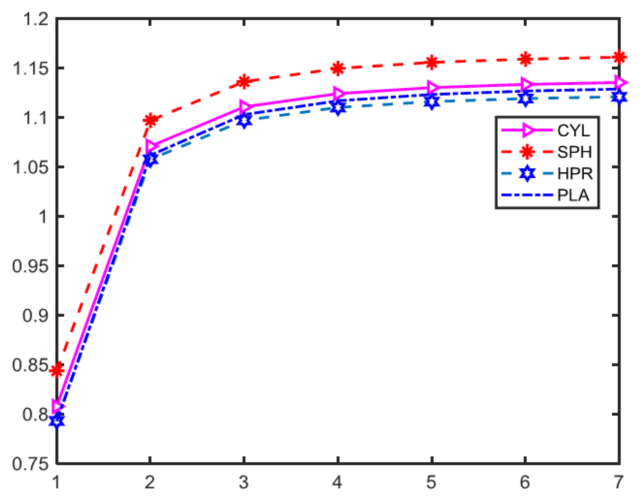

(a)

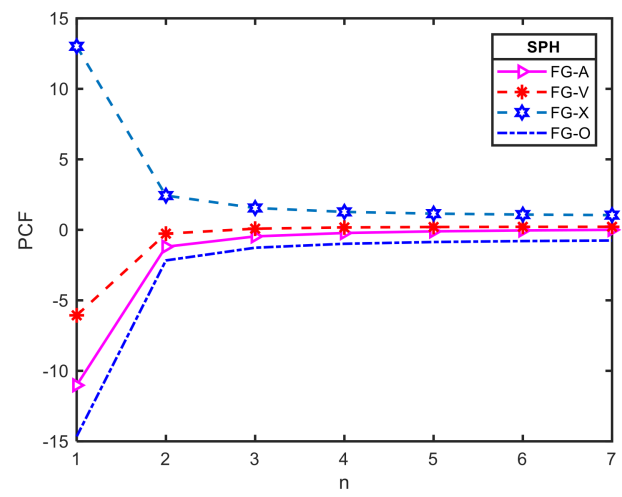

(b)

Figure 7. Effect of number of layers (n) on free vibration of FG-CNTRC shell panels $\left(a / b=1, R_{x}=R_{y}=R\right.$; $V_{C N T}^{*}=0.17,(0 / 90)_{n}$ : (a) For the frequency parameter $\hat{\omega}=\omega a \sqrt{\frac{\rho^{m}}{E^{m}}} ;(\mathbf{b})$ for the percentage change of frequency $P C F$.

\subsubsection{Effect of Different Wave Numbers}

Table 4 listed non-dimensional frequencies for two-layered (0/90) FG-CNTRC doubly curved shell panels $\left(a / b=1 ; R / a=5, a / h=50, \mathrm{FG}-\mathrm{X}, V_{C N T}^{*}=0.17\right)$ for different wave numbers. It can be seen that at the small value of wave numbers $(n, m)$ the SPH panels have highest non-dimensional frequencies while the HPR panels have lowest ones. However, it also can be seen that the non-dimensional frequencies of all three types of doubly curved panels will approximately have more wave numbers.

Table 4. Non-dimensional frequencies $\bar{\omega}$ for two-layered (0/90) FG-CNTRC doubly curved shell panels for different wave numbers $\left(a / b=1 ; R / a=5, a / h=50\right.$, FG-X, $\left.V_{C N T}^{*}=0.17\right)$.

\begin{tabular}{|c|c|c|c|c|c|c|c|}
\hline Shape & $\mathbf{n}$ & $m=1$ & $m=2$ & $m=3$ & $m=4$ & $m=5$ & $m=6$ \\
\hline \multirow{6}{*}{ CYL } & 1 & 17.937 & 48.140 & 99.846 & 169.706 & 254.950 & 352.930 \\
\hline & 2 & 46.027 & 64.594 & 109.402 & 176.466 & 260.683 & 358.380 \\
\hline & 3 & 97.820 & 109.032 & 141.357 & 198.901 & 277.607 & 372.340 \\
\hline & 4 & 168.004 & 176.095 & 198.835 & 243.742 & 311.861 & 399.381 \\
\hline & 5 & 253.606 & 260.401 & 277.580 & 311.892 & 367.569 & 444.182 \\
\hline & 6 & 351.923 & 358.209 & 372.384 & 399.478 & 444.253 & 508.835 \\
\hline \multirow{6}{*}{$\mathrm{SPH}$} & 1 & 22.214 & 49.271 & 100.122 & 169.593 & 254.585 & 352.371 \\
\hline & 2 & 49.472 & 65.771 & 109.763 & 176.410 & 260.356 & 357.845 \\
\hline & 3 & 100.573 & 109.960 & 141.685 & 198.853 & 277.285 & 371.804 \\
\hline & 4 & 170.323 & 176.802 & 199.065 & 243.665 & 311.532 & 398.838 \\
\hline & 5 & 255.596 & 260.940 & 277.698 & 311.759 & 367.219 & 443.632 \\
\hline & 6 & 353.644 & 358.612 & 372.397 & 399.275 & 443.867 & 508.271 \\
\hline \multirow{6}{*}{ HPR } & 1 & 16.174 & 47.141 & 99.497 & 169.711 & 255.202 & 353.378 \\
\hline & 2 & 47.141 & 64.179 & 109.145 & 176.475 & 260.924 & 358.816 \\
\hline & 3 & 99.497 & 109.145 & 141.314 & 198.990 & 277.883 & 372.799 \\
\hline & 4 & 169.711 & 176.475 & 198.990 & 243.935 & 312.190 & 399.872 \\
\hline & 5 & 255.202 & 260.924 & 277.883 & 312.190 & 367.960 & 444.710 \\
\hline & 6 & 353.378 & 358.816 & 372.799 & 399.872 & 444.710 & 509.403 \\
\hline
\end{tabular}

Figures 8-10 depict the first six mode shapes of the simply supported laminated FG-CNTRC CYL, SPH and HPR shell panels, respectively. Geometric characteristics of the panels are $a / b=1, R / a=5$ and $a / h=50$. Type of CNT distribution is FG-X and volume faction of CNT is $V_{C N T}^{*}=0.17$. It can be noticed from these Figures, that in CYL panels, mode $(m=2, n=1)$ is higher than mode $(m=1, n=2)$, while in SPH and HPR panels, mode $(m=1, n=2)$ and mode $(m=2, n=1)$ are the same order. This is because the CYL panel only has the curvature in $x$ direction while SPH and HPR panels have the curvature 
in both $x$ and $y$ directions. These mode shapes can help to understand vibration characteristics of laminated FG-CNTRC doubly curved shell panels.

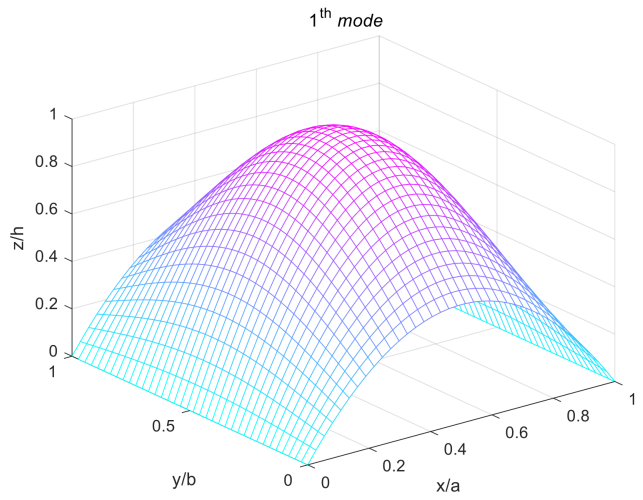

Mode $1(m=1 ; n=1)$

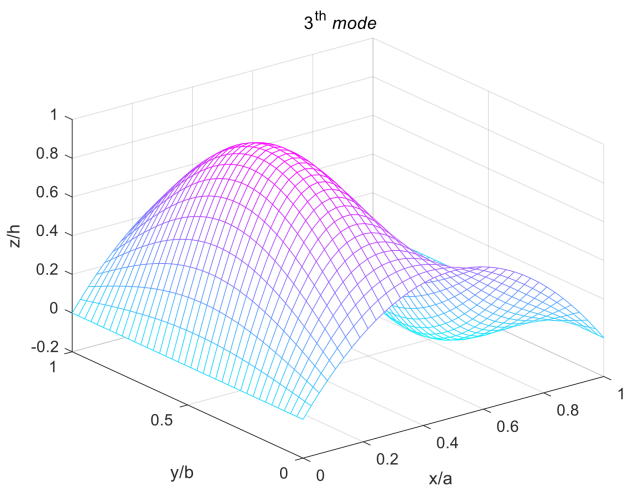

Mode $3(m=2 ; n=1)$

$5^{\text {th }}$ mode

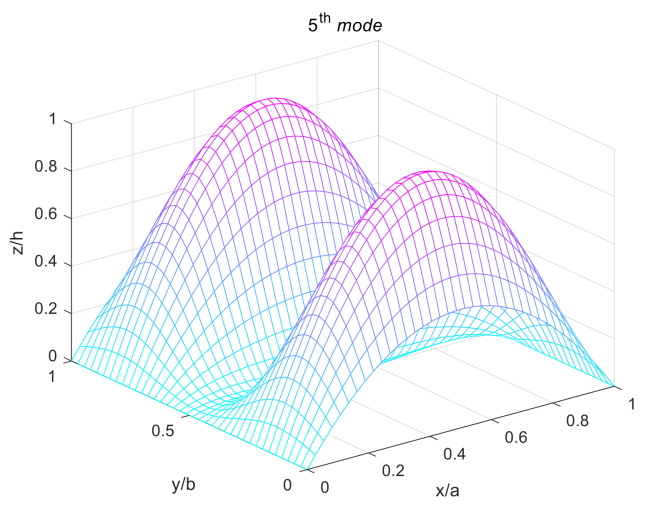

Mode $5(m=1 ; n=3)$

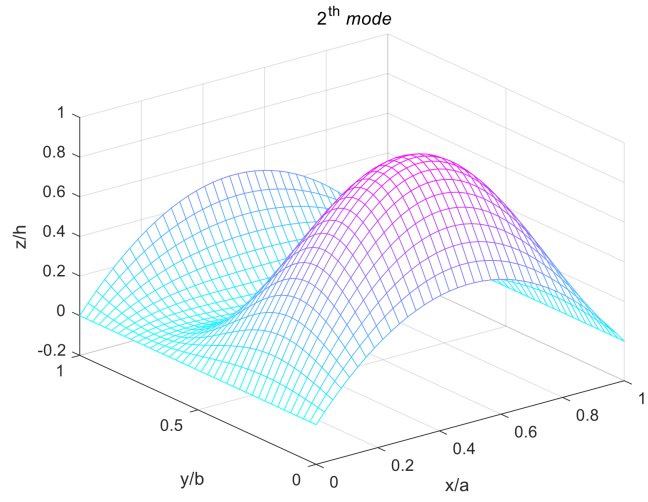

Mode $2(m=1 ; n=2)$

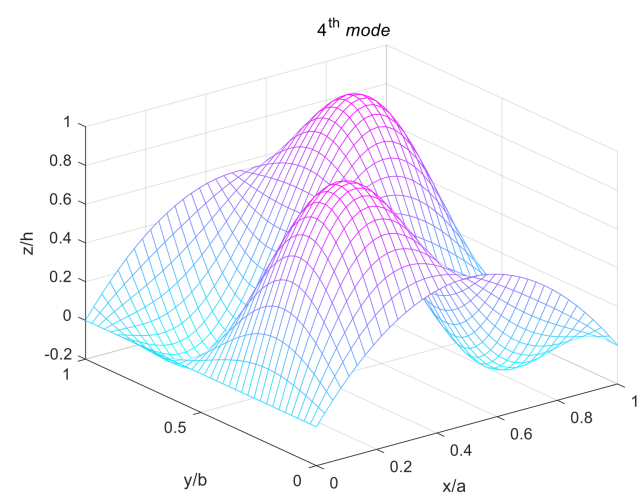

Mode $4(m=2 ; n=2)$

$6^{\text {th }}$ mode

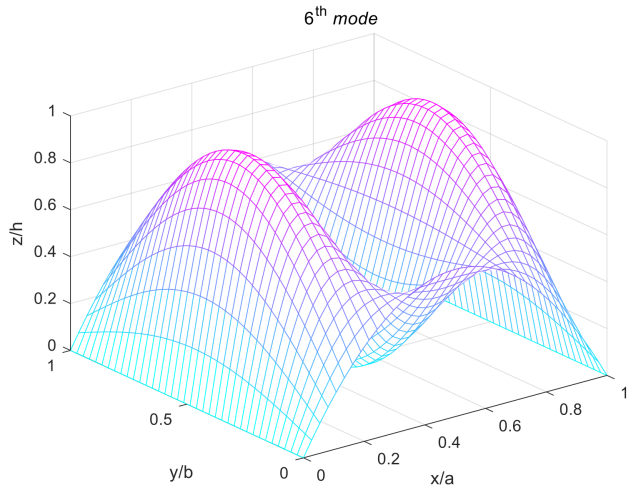

Mode $6(m=3 ; n=1)$

Figure 8. The first six mode shapes of simply supported laminated FG-CNTRC CYL panels. 


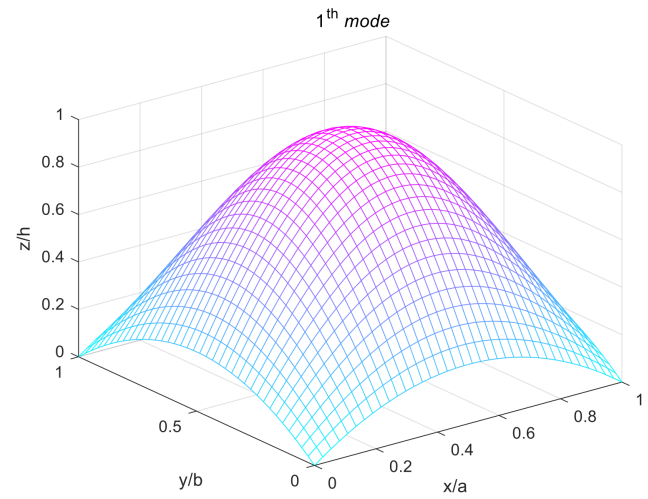

Mode $1(m=1 ; n=1)$

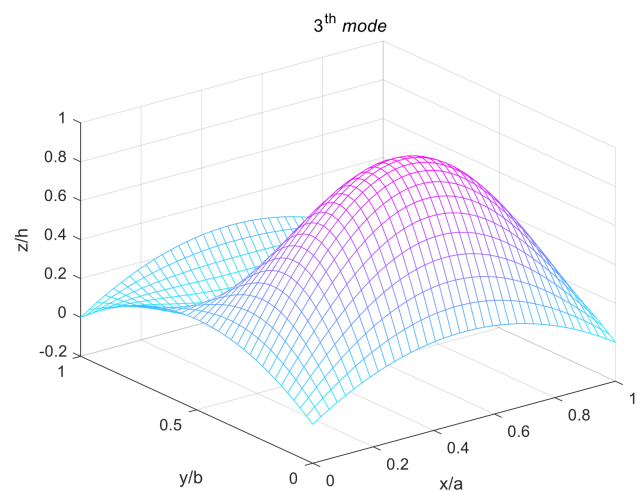

Mode $3(m=1 ; n=2)$

$5^{\text {th }}$ mode

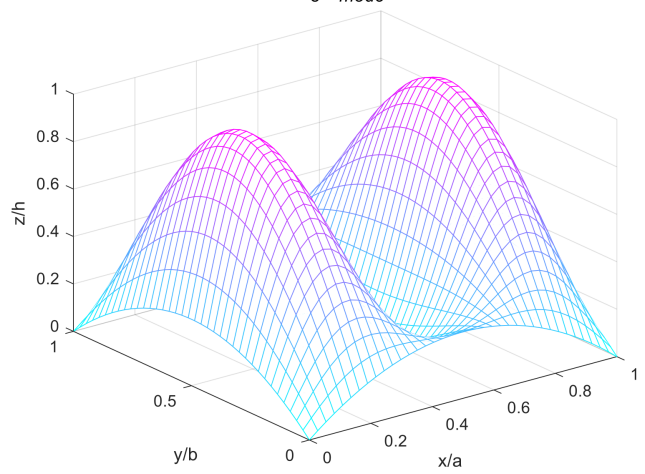

Mode $5(m=3 ; n=1)$

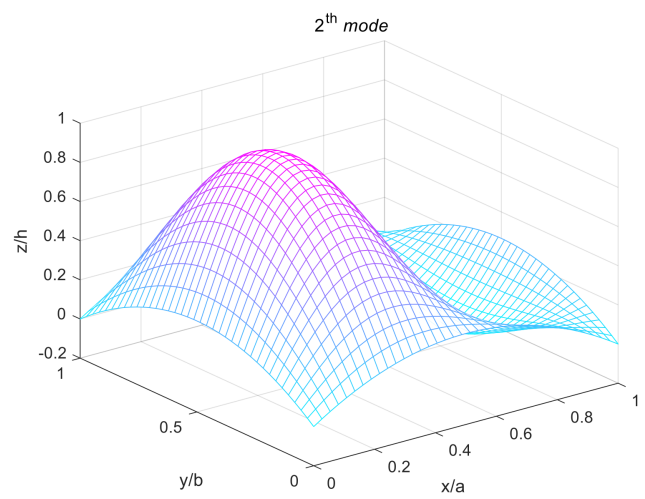

Mode $2(m=2 ; n=1)$

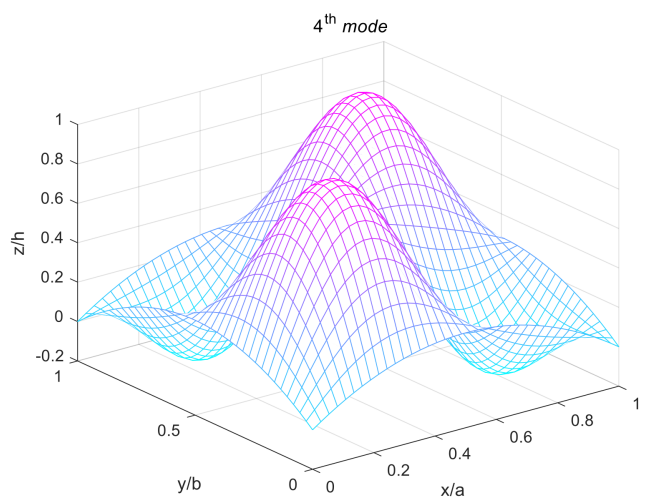

Mode $4(m=2 ; n=2)$

$6^{\text {th }}$ mode

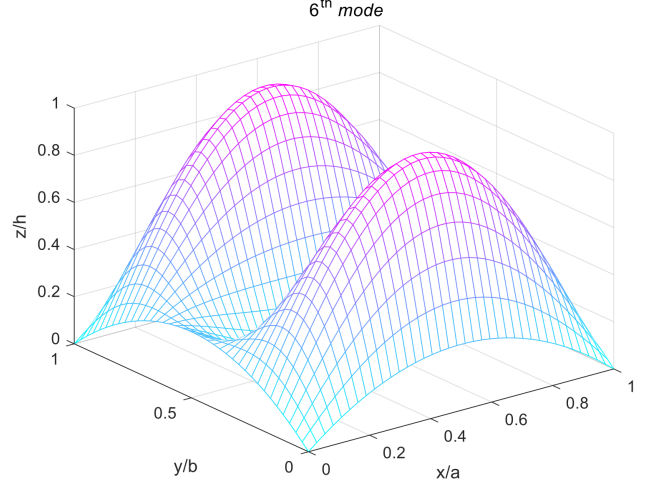

Mode $6(m=1 ; n=3)$

Figure 9. The first six mode shapes of simply supported laminated FG-CNTRC SPH panels. 


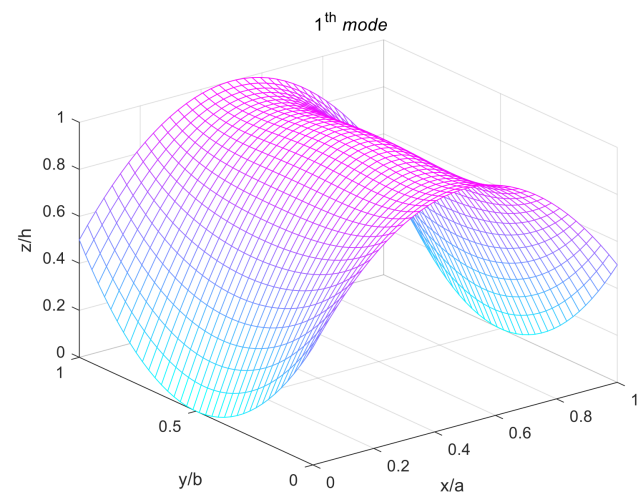

Mode $1(m=1 ; n=1)$

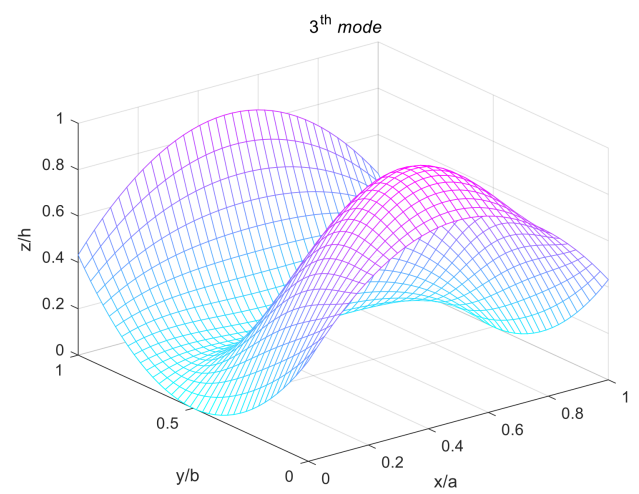

Mode $3(m=1 ; n=2)$

$$
5^{\text {th }} \text { mode }
$$

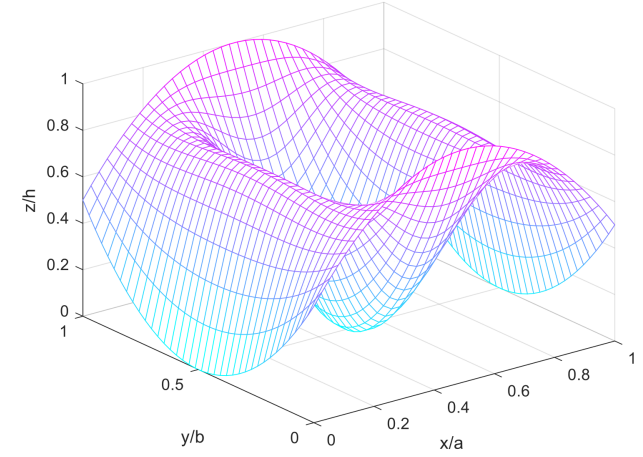

Mode $5(m=3 ; n=1)$

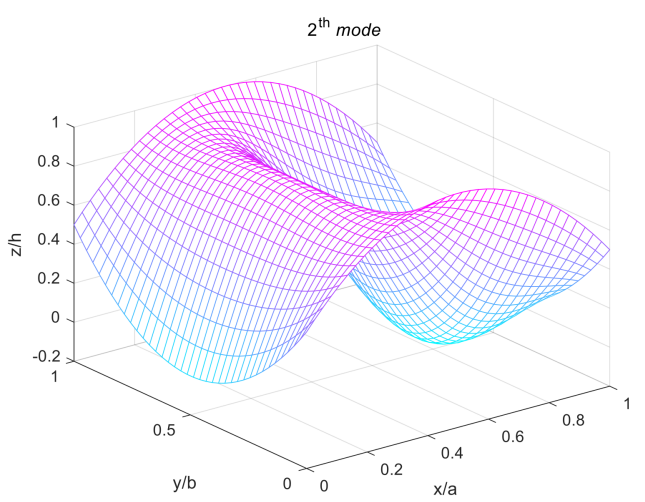

Mode $2(m=2 ; n=1)$

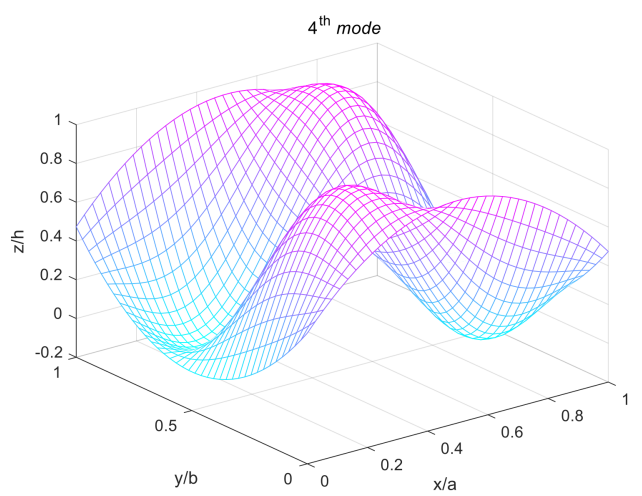

Mode $4(m=2 ; n=2)$ $6^{\text {th }}$ mode

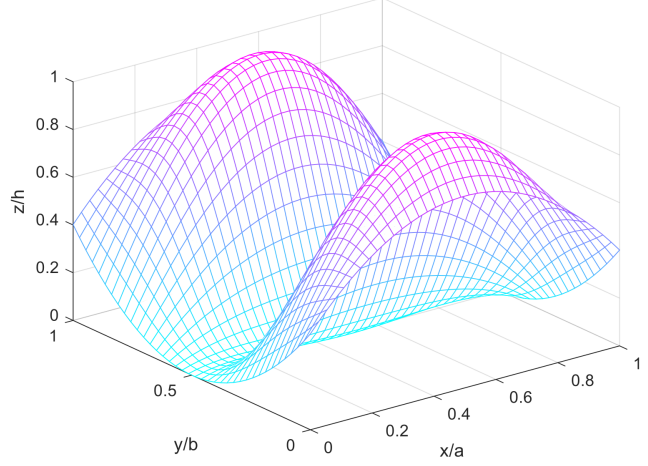

Mode $6(m=1 ; n=3)$

Figure 10. The first six mode shapes of simply supported laminated FG-CNTRC HPR panels.

\section{Conclusions}

In this paper, an analytical solution based on a new four-variable refined shell theory for free vibration analysis of the laminated FG-CNTRC doubly curved shell panels was developed. The accuracy and efficiency of the present model are validated through a review of comparison studies. The influences of several parameters such as FG-CNTRC parameters, curvature, curvature ratio, thickness ratio, aspect ratio and the number of layers on free vibration responses of the panels are explored. The results revealed that the shell panels become stiffer with increasing curvature, conversely, the stiffness of the panels is reduced as the aspect ratio increases. FG-X CNTRC panels have the highest frequency, while FG-O CNTRC panels have the smallest frequency regarding all inlet studied parameters. 
The present theory is accurate and efficient in solving free vibration behaviours of doubly curved laminated FG-CNT reinforced composite panels and may be useful in the study of similar composite structures.

Author Contributions: Formal analysis, Software, V.V.T.; Writing-original draft, Investigation, T.H.Q.; Supervision-editing, T.M.T.

Funding: This research received no external funding.

Conflicts of Interest: The authors declared no potential conflicts of interest with respect to the research, authorship, and/or publication of this article.

\section{Appendix A}

Detailed steps to construct the new shape function:

The transverse strains associated with the displacement field in Equation (1) are:

$$
\begin{aligned}
\gamma_{x z} & =\frac{1}{1+z / R_{x}}\left[\frac{\partial w}{\partial x}+\frac{\partial u}{\partial z}-\frac{u_{0}}{R_{x}}\right]=\frac{1}{1+z / R_{x}}\left[\frac{\partial w_{b}}{\partial x}+\frac{\partial w_{s}}{\partial x}+\frac{u_{0}}{R_{x}}-\frac{\partial w_{b}}{\partial x}-f^{\prime}(z) \frac{\partial w_{s}}{\partial x}-\frac{u_{0}}{R_{x}}\right] \\
& =\frac{1}{1+z / R_{x}}\left[\left(1-f^{\prime}(z)\right) \frac{\partial w_{s}}{\partial x}\right] \\
\gamma_{y z} & =\frac{1}{1+z / R_{y}}\left[\frac{\partial w}{\partial y}+\frac{\partial v}{\partial z}-\frac{v_{0}}{R_{y}}\right]=\frac{1}{1+z / R_{y}}\left[\frac{\partial w_{b}}{\partial y}+\frac{\partial w_{s}}{\partial y}+\frac{v_{0}}{R_{y}}-\frac{\partial w_{b}}{\partial y}-f^{\prime}(z) \frac{\partial w_{s}}{\partial y}-\frac{v_{0}}{R_{y}}\right] \\
& =\frac{1}{1+z / R_{y}}\left[\left(1-f^{\prime}(z)\right) \frac{\partial w_{s}}{\partial y}\right]
\end{aligned}
$$

For shells under bending, the transverse shear stresses $\sigma_{x z}, \sigma_{y z}$ must be vanished at the top and bottom surfaces. These conditions lead to the requirement that the corresponding transverse strains on these surfaces have to be zero. From $\gamma_{x z}\left(x, y, \pm \frac{h}{2}\right)=\gamma_{y z}\left(x, y, \pm \frac{h}{2}\right)=0$, we obtain:

$$
\begin{aligned}
& \gamma_{x z}=\frac{1}{1+z / R_{x}}\left[\left(1-f^{\prime}(z)\right) \frac{\partial w_{s}}{\partial x}\right]=0 \text { at } z= \pm \frac{h}{2} \\
& \gamma_{y z}=\frac{1}{1+z / R_{y}}\left[\left(1-f^{\prime}(z)\right) \frac{\partial w_{s}}{\partial y}\right]=0 \text { at } z= \pm \frac{h}{2}
\end{aligned}
$$

From Equations (A2) and (A3), we have:

$$
f^{\prime}(z)=1 \text { at } z= \pm \frac{h}{2}
$$

Function $f(z)$ satisfies the condition (5) can be selected as a polynomial, trigonometric, and exponential, ... function. In our study, we chose $f(z)$ as a cubic polynomial: $f(z)=a z+\frac{b}{h^{2}} z^{3}$, thus:

$$
f^{\prime}(z)=a+\frac{3 b}{h^{2}} z^{2}=1
$$

Some authors have chosen the value of the pair $\mathrm{a}, \mathrm{b}$ to satisfy Equation (A5). In this study, we chose: $a=-1 / 8, b=3 / 2$. Thus:

$$
f(z)=-\frac{1}{8} z+\frac{3}{2} \frac{z^{3}}{h^{2}}, f^{\prime}(z)=\left.\left(-\frac{1}{8}+\frac{3.3}{2} \frac{z^{2}}{h^{2}}\right)\right|_{z= \pm \frac{h}{2}}=1
$$

\section{Appendix B}

Matrix elements of Equation (25):

$$
s_{11}=-\left(\bar{A}_{11}+2 \frac{\bar{B}_{11}}{R_{x}}+\frac{\bar{D}_{11}}{R_{x}^{2}}\right) \alpha_{m}^{2}-\left(\hat{A}_{66}+2 \frac{\hat{B}_{66}}{R_{x}}+\frac{\hat{D}_{66}}{R_{x}^{2}}\right) \beta_{n}^{2}
$$




$$
\begin{aligned}
& s_{12}=-\left(A_{12}+A_{66}+\left(B_{12}+B_{66}\right)\left(\frac{1}{R_{x}}+\frac{1}{R_{y}}\right)+\frac{1}{R_{x} R_{y}}\left(D_{12}+D_{66}\right)\right) \beta_{n} \alpha_{m} \\
& s_{14}=\left(\bar{B}_{11}^{s}+\frac{\bar{D}_{11}^{s}}{R_{x}}\right) \alpha_{m}{ }^{3}+\left(\left(B_{12}^{s}+B_{66}^{s}+\hat{B}_{66}^{s}+\frac{D_{66}^{s}}{R_{x}}+\frac{\hat{D}_{66}^{s}}{R_{x}}+\frac{D_{12}^{s}}{R_{x}}\right) \beta_{n}{ }^{2}+\frac{\bar{A}_{11}}{R_{x}}+\frac{A_{12}}{R_{y}}+\frac{\bar{B}_{11}}{R_{x}^{2}}+\frac{B_{12}}{R_{x} R_{y}}\right) \alpha_{m} \\
& s_{22}=-\left(\bar{A}_{66}+2 \frac{\bar{B}_{66}}{R_{y}}+\frac{\bar{D}_{66}}{R_{y}^{2}}\right) \alpha_{m}{ }^{2}-\left(\hat{A}_{22}+2 \frac{\hat{B}_{22}}{R_{y}}+\frac{\hat{D}_{22}}{R_{y}^{2}}\right) \beta_{n}{ }^{2} \\
& s_{23}=\left(\frac{A_{12}}{R_{x}}+\frac{\hat{A}_{22}}{R_{y}}+\frac{1}{R_{y}}\left(\frac{B_{12}}{R_{x}}+\frac{\hat{B}_{22}}{R_{y}}\right)\right) \beta_{n}+\left(\hat{B}_{22}+\frac{\hat{D}_{22}}{R_{y}}\right) \beta_{n}{ }^{3}+ \\
& \left(B_{12}+B_{66}+\bar{B}_{66}+\frac{1}{R_{y}}\left(D_{12}+D_{66}+\bar{D}_{66}\right)\right) \beta_{n} \alpha_{m}^{2} \\
& s_{24}=\left(\frac{A_{12}}{R_{x}}+\frac{\hat{A}_{22}}{R_{y}}+\frac{1}{R_{y}}\left(\frac{B_{12}}{R_{x}}+\frac{\hat{B}_{22}}{R_{y}}\right)\right) \beta_{n}+\left(\hat{B}_{22}^{s}+\frac{\hat{D}_{22}^{s}}{R_{y}}\right) \beta_{n}{ }^{3}+ \\
& \left(B_{12}^{s}+B_{66}^{s}+\bar{B}_{66}^{s}+\frac{1}{R_{y}}\left(D_{12}^{s}+D_{66}^{s}+\bar{D}_{66}^{s}\right)\right) \beta_{n} \alpha_{m}^{2} \\
& s_{33}=-\frac{\bar{A}_{11}}{R_{x}^{2}}-2 \frac{A_{12}}{R_{x} R_{y}}-\frac{\hat{A}_{22}}{R_{y}^{2}}-2\left(\frac{B_{12}}{R_{x}}+\frac{\hat{B}_{22}}{R_{y}}\right) \beta_{n}{ }^{2}-2\left(\frac{\bar{B}_{11}}{R_{x}}+\frac{B_{12}}{R_{y}}\right) \alpha_{m}{ }^{2}- \\
& \bar{D}_{11} \alpha_{m}{ }^{4}-\left(2 D_{12}+2 D_{66}+\bar{D}_{66}+\hat{D}_{66}\right) \alpha_{m}{ }^{2} \beta_{n}{ }^{2}-\hat{D}_{22} \beta_{n}{ }^{4} \\
& s_{34}=-\frac{\bar{A}_{11}}{R_{x}^{2}}-2 \frac{A_{12}}{R_{x} R_{y}}-\frac{\hat{A}_{22}}{R_{y}^{2}}-\left(\frac{\bar{B}_{11}}{R_{x}}+\frac{\bar{B}_{11}^{s}}{R_{x}}+\frac{B_{12}}{R_{y}}+\frac{B_{12}^{s}}{R_{y}}\right) \alpha_{m}{ }^{2}-\left(\frac{B_{12}}{R_{x}}+\frac{B_{12}^{s}}{R_{x}}+\frac{\hat{B}_{22}}{R_{y}}+\frac{\hat{B}_{22}^{s}}{R_{y}}\right) \beta_{n}{ }^{2}- \\
& \left(2 D_{12}^{s}+2 D_{66}^{s}+\bar{D}_{66}^{s}+\hat{D}_{66}^{s}\right) \alpha_{m}{ }^{2} \beta_{n}{ }^{2}-\bar{D}_{11}^{s} \alpha_{m}{ }^{4}-\hat{D}_{22}^{s} \beta_{n}{ }^{4} \\
& s_{13}=\left(\frac{\bar{A}_{11}}{R_{x}}+\frac{A_{12}}{R_{y}}+\frac{1}{R_{x}}\left(\frac{\bar{B}_{11}}{R_{x}}+\frac{B_{12}}{R_{y}}\right)\left(B_{12}+B_{66}+\hat{B}_{66}+\frac{1}{R_{x}}\left(D_{12}+D_{66}+\hat{D}_{66}\right)\right) \beta_{n}{ }^{2}\right) \alpha_{m}+ \\
& \left(\bar{B}_{11}+\frac{\bar{D}_{11}}{R_{x}}\right) \alpha_{m}{ }^{3} \\
& s_{44}=-\frac{\bar{A}_{11}}{R_{x}^{2}}-2 \frac{A_{12}}{R_{x} R_{y}}-\frac{\hat{A}_{22}}{R_{y}^{2}}-\left(\hat{A}_{44}^{s}+2 \frac{B_{12}^{s}}{R_{x}}+2 \frac{\hat{B}_{22}^{s}}{R_{y}}\right) \beta_{n}{ }^{2}-\left(\bar{A}_{55}^{s}+2 \frac{\bar{B}_{11}^{s}}{R_{x}}+2 \frac{B_{12}^{s}}{R_{y}}\right) \alpha_{m}{ }^{2}- \\
& \left(2 E_{12}^{s}+2 E_{66}^{s}+\bar{E}_{66}^{s}+\hat{E}_{66}^{s}\right) \alpha_{m}{ }^{2} \beta_{n}{ }^{2}-\bar{E}_{11}^{s} \alpha_{m}{ }^{4}-\hat{E}_{22}^{s} \beta_{n}{ }^{4} \\
& m_{11}=-\left(\bar{I}_{0}+2 \frac{\bar{I}_{1}}{R_{x}}+\frac{\bar{I}_{2}}{R_{x}^{2}}\right) ; m_{12}=0 ; m_{13}=\left(\bar{I}_{1}+\frac{\bar{I}_{2}}{R_{x}}\right) \alpha_{m} ; m_{14}=\left(\bar{J}_{1}+\frac{\bar{J}_{2}}{R_{x}}\right) \alpha_{m} ; \\
& m_{11}=-\left(\bar{I}_{0}+2 \frac{\bar{I}_{1}}{R_{y}}+\frac{\bar{I}_{2}}{R_{y}^{2}}\right) ; m_{23}=\left(\bar{I}_{1}+\frac{\bar{I}_{2}}{R_{y}}\right) \beta_{n} ; m_{24}=\left(\bar{J}_{1}+\frac{\bar{J}_{2}}{R_{y}}\right) \beta_{n} ; \\
& m_{33}=-\bar{I}_{0}-\bar{I}_{2}\left(\alpha_{m}{ }^{2} \beta_{n}{ }^{2}\right) ; m_{34}=-\bar{I}_{0}-\bar{I}_{2}\left(\alpha_{m}{ }^{2} \beta_{n}{ }^{2}\right) ; m_{44}=-\bar{I}_{0}-\bar{K}_{1}\left(\alpha_{m}{ }^{2} \beta_{n}{ }^{2}\right) \text {; }
\end{aligned}
$$

\section{References}

1. Shen, H.-S. Nonlinear bending of functionally graded carbon nanotube-reinforced composite plates in thermal environments. Compos. Struct. 2009, 91, 9-19. [CrossRef]

2. Qatu, M.S. Theory and vibration analysis of laminated barrel thin shells. J. Vib. Control 1999, 5, 851-889. [CrossRef]

3. Reissner, E. A new derivation of the equations for the deformation of elastic shells. Am. J. Math. 1941, 63, 177-184. [CrossRef]

4. Bhimaraddi, A.; Stevens, L. A higher order theory for free vibration of orthotropic, homogeneous, and laminated rectangular plates. J. Appl. Mech. 1984, 51, 195. [CrossRef]

5. Eslami, M.; Shariyat, M. A high-order theory for dynamic buckling and postbuckling analysis of laminated cylindrical shells. J. Press. Vessel. Technol. 1999, 12, 94-102. [CrossRef]

6. Rahmani, O.; Khalili, S.; Thomsen, O.T. A high-order theory for the analysis of circular cylindrical composite sandwich shells with transversely compliant core subjected to external loads. Compos. Struct. 2012, 94, 2129-2142. [CrossRef]

7. Shimpi, R.; Patel, H. Free vibrations of plate using two variable refined plate theory. J. Sound Vib. 2006, 296, 979-999. [CrossRef] 
8. El Meiche, N.; Tounsi, A.; Ziane, N.; Mechab, I. A new hyperbolic shear deformation theory for buckling and vibration of functionally graded sandwich plate. Int. J. Mech. Sci. 2011, 53, 237-247. [CrossRef]

9. Thai, H.-T.; Vo, T.P. A new sinusoidal shear deformation theory for bending, buckling, and vibration of functionally graded plates. Appl. Math. Model. 2013, 37, 3269-3281. [CrossRef]

10. Thai, H.T.; Kim, S.E. A simple quasi-3D sinusoidal shear deformation theory for functionally graded plates. Compos. Struct. 2013, 99, 172-180. [CrossRef]

11. Daouadji, T.H.; Tounsi, A. A new higher order shear deformation model for static behavior of functionally graded plates. Adv. Appl. Math. Mech. 2013, 5, 351-364. [CrossRef]

12. Mehrabadi, S.J.; Aragh, B.S. Stress analysis of functionally graded open cylindrical shell reinforced by agglomerated carbon nanotubes. Thin Walled Struct. 2014, 80, 130-141. [CrossRef]

13. Aragh, B.S.; Barati, A.N.; Hedayati, H. Eshelby-Mori-Tanaka approach for vibrational behavior of continuously graded carbon nanotube-reinforced cylindrical panels. Compos. Part B Eng. 2012, 43, 1943-1954. [CrossRef]

14. Yas, M.; Pourasghar, A.; Kamarian, S.; Heshmati, M. Three-dimensional free vibration analysis of functionally graded nanocomposite cylindrical panels reinforced by carbon nanotube. Mater. Des. 2013, 49, 583-590. [CrossRef]

15. Alibeigloo, A. Free vibration analysis of functionally graded carbon nanotube-reinforced composite cylindrical panel embedded in piezoelectric layers by using theory of elasticity. Eur. J. Mech. A/Solids 2014, 44, 104-115. [CrossRef]

16. Lei, Z.; Zhang, L.; Liew, K.; Yu, J. Dynamic stability analysis of carbon nanotube-reinforced functionally graded cylindrical panels using the element-free kp-Ritz method. Compos. Struct. 2014, 113, 328-338. [CrossRef]

17. Moradi-Dastjerdi, R.; Foroutan, M.; Pourasghar, A. Dynamic analysis of functionally graded nanocomposite cylinders reinforced by carbon nanotube by a mesh-free method. Mater. Des. 2013, 44, 256-266. [CrossRef]

18. Shen, H.S.; Xiang, Y. Nonlinear vibration of nanotube-reinforced composite cylindrical panels resting on elastic foundations in thermal environments. Compos. Struct. 2014, 111, 291-300. [CrossRef]

19. Shen, H.S.; Xiang, Y. Postbuckling of nanotube-reinforced composite cylindrical shells under combined axial and radial mechanical loads in thermal environment. Compos. Part B Eng. 2013, 52, 311-322. [CrossRef]

20. Shen, H.-S. Thermal buckling and postbuckling behavior of functionally graded carbon nanotube-reinforced composite cylindrical shells. Compos. Part B Eng. 2012, 43, 1030-1038. [CrossRef]

21. Shen, H.-S. Torsional postbuckling of nanotube-reinforced composite cylindrical shells in thermal environments. Compos. Struct. 2014, 116, 477-488. [CrossRef]

22. Liew, K.; Lei, Z.; Yu, J.; Zhang, L. Postbuckling of carbon nanotube-reinforced functionally graded cylindrical panels under axial compression using a meshless approach. Comput. Methods Appl. Mech. Eng. 2014, 268, 1-17. [CrossRef]

23. Lei, Z.; Zhang, L.; Liew, K. Parametric analysis of frequency of rotating laminated CNT reinforced functionally graded cylindrical panels. Compos. Part B Eng. 2016, 90, 251-266. [CrossRef]

24. Tornabene, F.; Fantuzzi, N.; Bacciocchi, M.; Viola, E. Effect of agglomeration on the natural frequencies of functionally graded carbon nanotube-reinforced laminated composite doubly-curved shells. Compos. Part $B$ Eng. 2016, 89, 187-218. [CrossRef]

25. Thomas, B.; Roy, T. Vibration and damping analysis of functionally graded carbon nanotubes reinforced hybrid composite shell structures. J. Vib. Control 2017, 23, 1711-1738. [CrossRef]

26. Arani, A.G.; Kiani, F.; Afshari, H. Free and forced vibration analysis of laminated functionally graded CNT-reinforced composite cylindrical panels. J. Sandw. Struct. Mater. 2019, 1099636219830787. [CrossRef]

27. Lei, Z.; Zhang, L.; Liew, K. Analysis of laminated CNT reinforced functionally graded plates using the element-free kp-Ritz method. Compos. Part B Eng. 2016, 84, 211-221. [CrossRef]

28. Thai, H.T.; Kim, S.E. A simple higher-order shear deformation theory for bending and free vibration analysis of functionally graded plates. Compos. Struct. 2013, 96, 165-173. [CrossRef]

29. Huu Quoc, T.; Minh Tu, T.; Van Tham, V. Free vibration analysis of smart laminated functionally graded CNT reinforced composite plates via new four-variable refined plate theory. Materials 2019, 12, 3675. [CrossRef]

30. Qatu, M.S. Vibration of Laminated Shells and Plates; Elsevier: Amsterdam, The Netherlands, 2004.

31. Reddy, J.N. Mechanics of Laminated Composite Plates and Shells: Theory and Analysis; CRC Press: Boka Raton, FL, USA, 2003. 
32. Reddy, J.N. Energy Principles and Variational Methods in Applied Mechanics; John Wiley \& Sons: Hoboken, NJ, USA, 2017.

33. Wang, Q.; Shao, D.; Qin, B. A simple first-order shear deformation shell theory for vibration analysis of composite laminated open cylindrical shells with general boundary conditions. Compos. Struct. 2018, 184, 211-232. [CrossRef]

34. Pouresmaeeli, S.; Fazelzadeh, S. Frequency analysis of doubly curved functionally graded carbon nanotube-reinforced composite panels. Acta Mech. 2016, 227, 2765-2794. [CrossRef]

35. Huang, B.; Guo, Y.; Wang, J.; Du, J.; Qian, Z.; Ma, T.; Yi, L. Bending and free vibration analyses of antisymmetrically laminated carbon nanotube-reinforced functionally graded plates. J. Compos. Mater. 2017, 51, 3111-3125. [CrossRef]

(C) 2019 by the authors. Licensee MDPI, Basel, Switzerland. This article is an open access article distributed under the terms and conditions of the Creative Commons Attribution (CC BY) license (http://creativecommons.org/licenses/by/4.0/). 